\title{
BMJ Open Incidence of adverse events in paediatric procedural sedation in the emergency department: a systematic review and meta-analysis
}

\author{
M Fernanda Bellolio, ${ }^{1,2}$ Henrique A Puls, ${ }^{3}$ Jana L Anderson, ${ }^{1}$ Waqas I Gilani, ${ }^{1}$ \\ M Hassan Murad, ${ }^{2,4,5}$ Patricia Barrionuevo, ${ }^{2,5}$ Patricia J Erwin, ${ }^{6}$ Zhen Wang, ${ }^{2,5}$ \\ Erik P Hess ${ }^{1,2}$
}

To cite: Bellolio MF, Puls HA, Anderson JL, et al. Incidence of adverse events in paediatric procedural sedation in the emergency department: a systematic review and meta-analysis. BMJ Open 2016;6:e011384. doi:10.1136/bmjopen-2016011384

- Prepublication history and additional material is available. To view please visit the journal (http://dx.doi.org/ 10.1136/bmjopen-2016011384).

Received 4 February 2016 Revised 6 May 2016 Accepted 23 May 2016

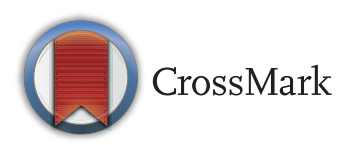

For numbered affiliations see end of article.

Correspondence to Dr M Fernanda Bellolio; Bellolio.fernanda@mayo.edu

\section{ABSTRACT}

Objective and design: We conducted a systematic review and meta-analysis to evaluate the incidence of adverse events in the emergency department (ED) during procedural sedation in the paediatric population. Randomised controlled trials and observational studies from the past 10 years were included. We adhere to the Preferred Reporting Items for Systematic Reviews and Meta-Analyses (PRISMA) statement.

Setting: ED.

Participants: Children.

Interventions: Procedural sedation.

Outcomes: Adverse events like vomiting, agitation, hypoxia and apnoea. Meta-analysis was performed with random-effects model and reported as incidence rates with $95 \% \mathrm{Cls}$.

Results: A total of 1177 studies were retrieved for screening and 258 were selected for full-text review. 41 studies reporting on 13883 procedural sedations in 13876 children ( $\leq 18$ years) were included. The most common adverse events (all reported per 1000 sedations) were: vomiting 55.5 ( $\mathrm{Cl} 45.2$ to 65.8$)$, agitation 17.9 (Cl 12.2 to 23.7$)$, hypoxia 14.8 (Cl 10.2 to 19.3) and apnoea 7.1 ( $\mathrm{Cl} 3.2$ to 11.0). The need to intervene with either bag valve mask, oral airway or positive pressure ventilation occurred in 5.0 per 1000 sedations ( $\mathrm{Cl} 2.3$ to 7.6). The incidences of severe respiratory events were: 34 cases of laryngospasm among 8687 sedations (2.9 per 1000 sedations, $\mathrm{Cl} 1.1$ to 4.7 ; absolute rate 3.9 per 1000 sedations), 4 intubations among 9136 sedations and 0 cases of aspiration among 3326 sedations. 33 of the 34 cases of laryngospasm occurred in patients who received ketamine.

Conclusions: Serious adverse respiratory events are very rare in paediatric procedural sedation in the ED. Emesis and agitation are the most frequent adverse events. Hypoxia, a late indicator of respiratory depression, occurs in $1.5 \%$ of sedations. Laryngospasm, though rare, happens most frequently with ketamine. The results of this study provide quantitative risk estimates to facilitate shared decisionmaking, risk communication, informed consent and

\section{Strengths and limitations of this study}

- This is a large systematic review and meta-analysis of current data on procedural sedation in children and adheres to recommendations made in the Preferred Reporting Items for Systematic Reviews and Meta-Analyses (PRISMA) statement.

- We searched MEDLINE, EMBASE, EBSCO, CINAHL, CENTRAL, the Cochrane Database of Systematic Reviews, Web of Science and Scopus from inception through June 2014 without language restrictions.

- Randomised controlled trials and observational studies of procedural sedations in the emergency department were included. We did not search for unpublished literature or ongoing trials.

- Restriction to paediatric population (younger than 18 years of age).

- There was lack of standardisation and variation in the definition of the outcomes.

resource allocation in children undergoing procedural sedation in the ED.

\section{INTRODUCTION}

Procedural sedation and analgesia (PSA) in the emergency department (ED) is frequently performed for painful or potentially agitating procedures performed on children. ${ }^{1}$ Several large paediatric studies have investigated the use of PSA in a variety of settings outside of the operating room. ${ }^{2-4}$ PSA performed in the $\mathrm{ED}$ is distinctive from other settings in that the procedures performed are likely to be more painful and urgent in nature. ${ }^{3}$ Over the past decade, PSA in the ED has been in a relative steady state regarding the guidelines set forth and the 
monitoring performed ${ }^{5-7}$ In addition, there has been a move to standardise reporting of adverse sedation events. ${ }^{8}$ Despite the advance in monitoring and medication selection, there is no single 'safe' and 'risk-free' medication for PSA. ${ }^{10-12}$

The behaviour and developmental stage of a child makes PSA in children distinct from that of adults. Although similar medications are frequently used, doses are higher in children relative to body weight. ${ }^{13}$ Frequently, a deeper level of sedation is necessary to perform a procedure on a child compared with an adult. ${ }^{1}$ Children inherently have a habitus that is prone to adverse events. ${ }^{14}$ They have a larger occiput, which makes positioning of the airway more challenging. They have a relatively larger tongue and upper airway soft tissue that can occlude the airway. ${ }^{15}$ The airway of a child also has higher resistance due to a funnel-shaped glottis. ${ }^{16}$ They have a higher metabolic demand, resulting in the rapid development of hypercarbia and hypoxia after apnoea. ${ }^{17}$ All of these factors add to the challenge of performing PSA safely in children.

Much of the current PSA literature has focused on the use of medication combinations, comparison to a single agent and/or use of different routes of administration. $^{18-20}$ We conducted a systematic review and meta-analysis to determine the incidence of adverse events during PSA in children in the ED, including the frequency of events associated with individual drugs and different drug combinations. We anticipate that the results of the review will provide useful information to providers when performing procedural sedation in a given patient, engaging in risk communication, shared decision-making and in the informed consent process.

\section{METHODS}

\section{Study design}

This is a systematic review and meta-analysis of studies reporting rates of adverse events for commonly used sedation drugs in the ED. A protocol was written before beginning the investigation. This report adheres to recommendations made in the Preferred Reporting Items for Systematic Reviews and Meta-Analyses (PRISMA) statement. ${ }^{21}$

\section{Eligibility criteria}

\section{Types of studies}

We included original research studies, including randomised controlled trials (RCTs) and cohort studies, in which procedural sedation (PSA) was performed on children in the ED. Only studies with children younger than 18 years of age were included. The study included children younger than 18 years. We did not exclude any studies based on language. Studies published in the past 10 years were included. This time restriction was based on the availability of capnography and increased standardisation of PSA. Details of articles excluded on the basis of publication date (from 1966 until 2004) are available in online supplementary appendix 1a. Information about the included studies can be found in online supplementary appendix $1 \mathrm{~b}$.

\section{Types of patients and procedures}

Studies of patients younger than 18 years of age who underwent PSA in the ED were included. All types of medications used for PSA were included. Procedures included: orthopaedic joint or fracture reductions, laceration repairs, chest tube insertion, electrical cardioversion, abscess incision and drainage, upper endoscopy, feeding tube replacement, lumbar puncture, arthrocentesis, foreign body removal, burn wound care, hernia reduction, stool disimpaction, urinary catheter placement, central line placement, nasopharyngoscopy, peritonsillar abscess drainage, pelvic examination, paraphimosis reduction, prolapse reduction, bone marrow aspiration, ophthalmological examination and obtaining CT or MRI.

\section{Types of interventions}

To meet the inclusion criteria, sedation had to be performed in the ED by emergency providers, including emergency medicine residents, staff physicians and/or advance practice providers (nurse practitioners or physician assistants). Any drug alone or in combination, given by any route (intravenous, intramuscular, inhalational, intranasal or oral), was included. Studies where the aim was anxiolysis alone were not included. Only studies in which PSA was attempted for moderate-to-deep sedation were included.

\section{Outcome measures}

In determining which adverse events to abstract and report, we followed previously reported outcomes in the PSA literature. The following outcomes were included: agitation, apnoea, aspiration, bradycardia, bag valve mask (BVM)/positive pressure ventilation, hypotension, hypoxia, intubation, laryngospasm, myoclonus, vomiting and oral airway placement. Subclinical respiratory depression was defined as a loss of end-tidal carbon dioxide $\left(\mathrm{ETCO}_{2}\right)$ waveform; change in $\mathrm{ETCO}_{2}$ of $>10 \mathrm{~mm} \mathrm{Hg}$ or as reported per each individual study was recorded but not analysed as an outcome.

\section{Search strategy}

A senior expert librarian designed and conducted a comprehensive search of eight electronic databases, including Ovid MEDLINE, Ovid EMBASE, EBSCO CINAHL, Ovid CENTRAL, the Ovid Cochrane Database of Systematic Reviews, Web of Science and Scopus from inception to June 2014. The Medline search strategy is included in online supplementary appendix 2 . We searched for published conference abstracts. We did not search the grey literature including reports or dissertations, ongoing or unpublished research or expert opinion. We did not apply any language restrictions to the search strategy. 


\section{Study selection}

In phase I, two investigators, working independently, screened all titles and abstracts for eligibility. Records considered potentially relevant were retrieved in full text and assessed for eligibility by two independent reviewers in phase II. We used Cohen's unweighted $\kappa$ to measure chance corrected agreement between reviewers for phase II of the study selection. Any disagreements were discussed with the lead author and resolved by consensus.

\section{Data extraction}

Data were extracted independently and in duplicate using a standardised data form. Disagreements were resolved by discussion and consensus. Data collected included study design and the incidence of each reported adverse event. Data were compared between the two reviewers, and discrepancies were resolved through discussion.

We collected details regarding medications used including whether a single drug was used (eg, propofol) or a combination of drugs (eg, propofol/ketamine). We recorded the total number of patients experiencing events and the total number of procedures performed.

\section{Risk of bias assessment}

For RCTs, we assessed the risk of bias using the Cochrane Collaboration Bias Appraisal Tool. ${ }^{22}$ We assessed the risk of bias for cohort studies using the Newcastle-Ottawa Scale. ${ }^{23}$

\section{Missing data}

We collected the outcomes included in the published reports. We contacted authors by email if data were missing or unclear. If data were still missing after attempting to contact the author, we classified the study as unclear. If data were not reported for a particular outcome, this was recorded in the data abstraction form.

\section{Data synthesis}

We used the 'OpenMetaAnalyst' software ${ }^{24}$ for meta-analyses using a random-effects model as described by DerSimonian-Laird. $\mathrm{I}^{2}$ was used to quantify the degree of statistical heterogeneity between studies. For studies with a low frequency of events (zero events), we used the modified Wald method to calculate CIs. We estimated the incidence per 1000 patients with $95 \%$ CIs. We measured the interobserver reliability of phase II of the study selection process using Cohen's unweighted $\kappa$.

To account for the clinical and statistical heterogeneity between studies, we used a random-effects model. A random-effects model uses a different formula to calculate more conservative $95 \%$ CIs. The effects of treatment are assumed to vary around some overall average treatment effect, as opposed to a fixed-effects model, in which it is assumed that each study has the same fixed common treatment effect.
We performed the following a priori sensitivity analysis: the incidence of adverse events reported in RCTs.

\section{RESULTS}

\section{Description of included studies}

Figure 1 shows the study selection process. The search strategy identified 1177 studies for review. After screening the titles and abstracts and removing duplicates, we identified 258 potentially relevant studies. After a fulltext review, 92 articles met the inclusion criteria. After excluding studies published before 2004, 41 articles including 13883 sedations conducted in 13876 children were included. Interobserver agreement $(\kappa)$ for phase II of the review was 0.99 (95\% CI 0.98 to 1.0 ).

\section{Study characteristics}

Thirteen were RCTs and 28 were observational studies. The studies included 13883 PSAs conducted in 13876 children, with $<0.1 \%$ undergoing more than one PSA (online supplementary appendix $1 \mathrm{~b}$ ).

\section{Quality and risk of bias assessment}

The quality of randomised trials using Cochrane Collaboration's tool for assessing the risk of bias is included in online supplementary appendix 3 , and the quality of cohort studies using the Newcastle-Ottawa Scale is included in online supplementary appendix 4. Most studies had a moderate risk of bias. We did not exclude articles based on the quality assessment.

We assessed clinical heterogeneity by determining whether the characteristics of participants, interventions, outcome measures and timing of the outcome measurement were similar across studies. Sources of clinical heterogeneity included variable sample size between studies and different indications for sedation including: orthopaedic joint or fracture reductions, laceration repairs, chest tube insertion, abscess incision and drainage, upper endoscopy and lumbar puncture, among others. We did, however, consider it reasonable to pool the data, as these were all performed in the ED setting and required the patients to be sedated to tolerate the procedure. The timing for measurement of the outcomes was similar across studies, as sedation is a resourceintensive and closely monitored procedure.

We found a range from low to high statistical heterogeneity, with low statistical heterogeneity in the outcomes of aspiration, bradycardia and intubation $\left(\mathrm{I}^{2} 0 \%\right)$, hypotension $\left(\mathrm{I}^{2} 8 \%\right)$, apnoea $\left(\mathrm{I}^{2} 25 \%\right)$, BVM/oral airway/positive pressure ventilation $\left(\mathrm{I}^{2} 47 \%\right)$ and laryngospasm $\left(\mathrm{I}^{2} 40 \%\right)$. There was moderate-to-high statistical heterogeneity in the outcomes of agitation $\left(\mathrm{I}^{2} 75 \%\right)$, hypoxia $\left(\mathrm{I}^{2} 76 \%\right)$ and vomiting $\left(\mathrm{I}^{2} 85 \%\right)$.

\section{Outcomes}

A total of 13883 procedural sedations in children were included. Table 1 shows the incidence of adverse events per 1000 procedural sedations. The most common 


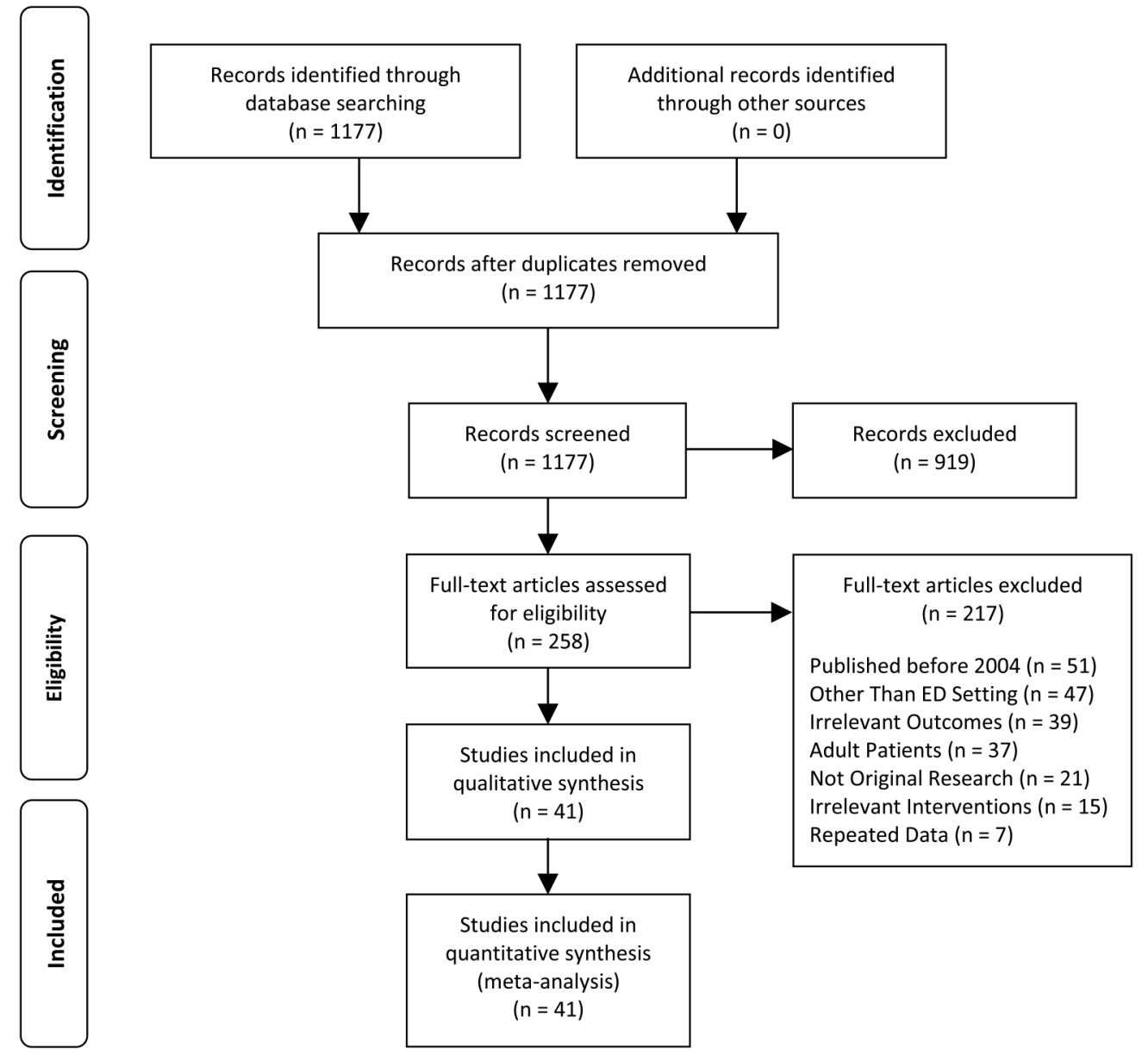

From: Moher D, Liberati A, Tetzlaff J, Altman DG, The PRISMA Group (2009). Preferred Reporting /tems for Systematic Reviews and MetaAnalyses: The PRISMA Statement. PLoS Med 6(6): e1000097. doi:10.1371/journal.pmed1000097

For more information, visit www. prisma-statement.org.

Figure 1 Flow diagram of study selection process. From 1177 records identified through database searching, 41 articles were eligible and included in the review. ED, emergency department.

adverse events (all reported per 1000 sedations) were: vomiting 55.5 (95\% CI 45.2 to 65.8 ), followed by agitation 17.9 (95\% CI 12.2 to 23.7), hypoxia 14.8 (95\% CI 10.2 to 19.3 ) and apnoea 7.1 (95\% CI 3.2 to 11.0$)$. The incidence of severe respiratory events was 0 cases of aspiration among 3326 sedations, 4 intubations among 9136 sedations and 34 laryngospasms among 8687 sedations.

\section{Agitation}

There were 175 (18.2 per 1000 sedations; 95\% CI 12.2 to 23.7) patients who developed agitation. A total of 6 of 1171 children received medication to treat agitation (3.1 per 1000 sedations). Studies using midazolam had the highest incidence of agitation. Propofol, nitrous oxide and etomidate had the lowest incidence of agitation (table 2 and figure 2). There were two studies that appear to be outliers in the plot. The study by Ghane et al reported sedation with intramuscular injection of midazolam in an ED in Iran. The authors report euphoria in $66.6 \%$ of the children and, in their discussion, acknowledge the high incidence of agitation and report that could be due to the race of the patients. The study by Oktay et al was performed in an ED in Turkey. They report 34 cases of recovery agitation including agitation, hallucinations, dysphoria, as well as pleasant and unpleasant dreams. The incidence was similar in the group with ketamine alone versus ketamine plus midazolam.

\section{Apnoea}

There were 38 events of apnoea in 6215 sedations with an incidence of 7.1 per 1000 sedations (95\% CI 3.2 to 11.0). Studies using propofol had the highest rate of apnoea, with an incidence of 34.3 for propofol/ketamine (95\% CI 0 to 96.8 ) and 15.0 (95\% CI 3.2 to 26.8) for propofol alone (table 2 and figure 3 ). 
Table 1 Incidence of adverse events per 1000 sedations (meta-analysis)

\begin{tabular}{|c|c|c|c|c|c|}
\hline & Number of events per sedations & Estimate per 1000 & Lower $\mathbf{C l}$ & Upper Cl & $I^{2}(\%)$ \\
\hline Agitation & $175 / 7226$ & 17.9 & 12.2 & 23.7 & 75 \\
\hline Apnoea & $38 / 6215$ & 7.1 & 3.2 & 11.0 & 25 \\
\hline Aspiration & $0 / 3326$ & 0.0 & 0.0 & 1.4 & 0 \\
\hline Bradycardia & $9 / 1315$ & 4.5 & 0.9 & 8.1 & 0 \\
\hline $\begin{array}{l}\text { BVM/oral airway/positive } \\
\text { pressure ventilation }\end{array}$ & $50 / 8760$ & 5.0 & 2.3 & 7.6 & 47 \\
\hline Hypotension & $12 / 2128$ & 2.2 & 0.0 & 4.3 & 8 \\
\hline Hypoxia & $238 / 11457$ & 14.8 & 10.2 & 19.3 & 76 \\
\hline Intubation & $4 / 9136$ & 0.4 & 0.0 & 0.8 & 0 \\
\hline Laryngospasm & $34 / 8687$ & 2.9 & 1.1 & 4.7 & 40 \\
\hline Vomiting & 498/7865 & 55.5 & 45.2 & 65.8 & 85 \\
\hline
\end{tabular}

\section{Aspiration}

There were no reported aspirations within the 3326 sedations, with an incidence of 0 per 1000 sedations (95\% CI 0 to 1.4).

\section{BVM ventilation, oral airway and positive pressure mask}

The composite outcome of BVM/oral airway/positive pressure ventilation was 50 events in 8760 patients with an incidence of 5.0 per 1000 sedations $(95 \%$ CI 2.3 to 7.6). Studies using propofol alone had the highest incidence (10.2 per 1000 sedations). Ketamine alone had an incidence of 6.9 per 1000 sedations. When propofol and ketamine were used together, the incidence was 5.3 per 1000 (95\% CI 0 to 13.4), shown in table 2 and figure 4 .

\section{Bradycardia}

A total of 1315 sedations reported the outcome of bradycardia. There were 9 (4.5 per 1000 sedations; 95\% CI 0.9 to 8.1 ) events of bradycardia. Studies using etomidate (66.7 per 1000 sedations) had the highest incidence of bradycardia (table 2 and figure 5 ).

\section{Hypotension}

There were 12 events of hypotension among 2128 sedations (2.2 per 1000 sedations; 95\% CI 0 to 4.3). Studies using propofol (37.3 per 1000 sedations) and etomidate (16.7 per 1000 sedations) had the highest incidence of hypotension (table 2 and figure 6 ).

\section{Hypoxia}

Hypoxia was reported in most of the studies, comprising 238 events in 11457 sedations. The overall incidence was 14.8 per 1000 sedations (95\% CI 10.2 to 19.3). The highest incidence of hypoxia occurred with etomidate (260.1 per 1000 sedations; 95\% CI 122.1 to 398.2), shown in table 2 and figure 7.

\section{Intubation}

There were 4 cases of intubation among 9136 sedations (0.4 per 1000 sedations; 95\% CI 0 to 0.8 ). Intubations were more common in studies that used propofol (5.3 per 1000 sedations), shown in table 2 and figure 8 .

\section{Laryngospasm}

A total of 8687 sedations reported the outcome of laryngospasm. Laryngospasm was reported in 34 patients (2.9 per 1000 sedations; $95 \%$ CI 1.1 to 4.7 ). Thirty-three of the 34 laryngospasms occurred in patients who received ketamine. Ketamine with propofol had the highest incidence at 4.6 per 1000 , followed by ketamine alone at 4.2 per 1000 sedations (table 2 and figure 9 ).

\section{Vomiting}

Vomiting occurred in 498 of 7865 sedations, with an incidence of 55.5 per 1000 sedations (95\% CI 45.2 to 65.8). Ketamine had the highest incidence of vomiting with 80.7 per 1000 sedations. When propofol and ketamine were used in combination, the incidence was 3.0 per 1000 sedations (Table 2 and figure 10).

\section{Sensitivity analyses}

When analysing the outcomes of RCTs, the incidence of events per 1000 sedations (95\% CI) was higher than the overall meta-analysis (95\% CI): hypoxia 42.5 (24.2 to 60.9 ); agitation 88.6 (39.7 to 137.4 ); apnoea 9.1 (1.8 to 16.4); hypotension 14.9 ( 0 to 36.5 ); laryngospasm $5.9(0$ to 14.4 ); and vomiting 100.2 (69.5 to 130.9$)$. There were no cases of bradycardia, intubations or aspirations reported in any of the RCTs.

\section{DISCUSSION}

Procedural sedation for children in the ED setting is an evolving process. ${ }^{25}$ The goal is to provide safe, effective PSA with minimal adverse events. With specific guidelines set forth by the American Academy of Pediatrics (AAP), the American College of Emergency Physicians (ACEP), the American Society of Anesthesiologists (ASA) and recommendations from the Joint Commission of Accreditation of Healthcare Organizations (JCAHO), there are set expectations on patient selection, practitioner skills and patient 
Table 2 Incidence of adverse events per 1000 sedations by medication used (meta-analysis)

\begin{tabular}{|c|c|c|c|c|c|c|c|}
\hline & Etomidate & Ketamine & $\begin{array}{l}\text { Ketamine/midazolam/ } \\
\text { +/-Opioid }\end{array}$ & $\begin{array}{l}\text { Ketamine/ } \\
\text { propofol }\end{array}$ & Midazolam & $\begin{array}{l}\text { Nitrous oxide } \\
\text { or chloral hydrate }\end{array}$ & Propofol \\
\hline \multicolumn{8}{|l|}{ Agitation } \\
\hline Events & $0 / 62$ & $73 / 2639$ & $24 / 598$ & $11 / 286$ & $24 / 119$ & $35 / 2964$ & $1 / 331$ \\
\hline Estimate per 1000 & 0 & 24.1 & 63.6 & 41.4 & 181.4 & 7.9 & 3.0 \\
\hline $95 \% \mathrm{Cl}$ & 0 to 69.8 & 13.3 to 34.9 & 10.4 to 116.8 & 0 to 83.7 & 2.4 to 360.3 & 4.0 to 11.8 & 0 to 8.9 \\
\hline $\mathrm{I}^{2}(\%)$ & 0 & 70 & 84 & 48 & 94 & 16 & 0 \\
\hline \multicolumn{8}{|l|}{ Apnoea } \\
\hline Events & $0 / 110$ & $20 / 4910$ & $1 / 108$ & $7 / 286$ & $0 / 50$ & 0/207 & $10 / 544$ \\
\hline Estimate per 1000 & 0 & 5.3 & 9.3 & 34.3 & 0 & 0 & 15.0 \\
\hline $95 \% \mathrm{Cl}$ & 0 to 40.5 & 0.4 to 10.3 & 0 to 27.3 & 0 to 96.8 & 0 to 85.2 & 0 to 21.9 & 3.2 to 26.8 \\
\hline $1^{2}(\%)$ & 0 & 16 & NA & 75 & NA & NA & 15 \\
\hline \multicolumn{8}{|l|}{ Aspiration } \\
\hline Events & $0 / 60$ & $0 / 802$ & $0 / 403$ & & $0 / 18$ & 0/1918 & $0 / 125$ \\
\hline Estimate per 1000 & 0 & 0 & 0 & & 0 & 0 & 0 \\
\hline $95 \% \mathrm{Cl}$ & 0 to 72 & 0 to 5.8 & 0 to 11.4 & & 0 to 206.7 & 0 to 2.4 & 0 to 35.8 \\
\hline $\mathrm{I}^{2}(\%)$ & NA & 0 & NA & & NA & 0 & NA \\
\hline \multicolumn{8}{|l|}{ Bradycardia } \\
\hline Events & $4 / 60$ & $1 / 299$ & $1 / 158$ & $2 / 219$ & & $0 / 248$ & $1 / 331$ \\
\hline Estimate per 1000 & 66.7 & 5.7 & 9.4 & 9.1 & & 0 & 3.0 \\
\hline $95 \% \mathrm{Cl}$ & 3.5 to 129.8 & 0 to 14.3 & 0 to 24.4 & 0 to 21.7 & & 0 to 18.4 & 0 to 8.9 \\
\hline $1^{2}(\%)$ & NA & 0 & 0 & NA & & 0 & 92 \\
\hline \multicolumn{8}{|l|}{ BVM/OA/PPV } \\
\hline Events & $0 / 110$ & $41 / 5375$ & $1 / 403$ & $1 / 306$ & $0 / 68$ & 0/1954 & $7 / 544$ \\
\hline Estimate per 1000 & 0 & 6.9 & 2.5 & 5.3 & 0 & 0 & 10.2 \\
\hline $95 \% \mathrm{Cl}$ & 0 to 40.5 & 4.7 to 9.1 & 0 to 7.3 & 0 to 13.4 & 0 to 64 & 0 to 2.4 & 0 to 21.4 \\
\hline $1^{2}(\%)$ & 0 & 0 & NA & 0 & 0 & 0 & 24 \\
\hline \multicolumn{8}{|l|}{ Hypotension } \\
\hline Events & $1 / 60$ & $0 / 505$ & $1 / 451$ & $0 / 219$ & $1 / 226$ & $0 / 248$ & 9/419 \\
\hline Estimate per 1000 & 16.7 & 0 & 1.4 & 0 & 2.7 & 0 & 37.3 \\
\hline $95 \% \mathrm{Cl}$ & 0 to 49.1 & 0 to 9.1 & 0 to 4.8 & 0 to 8.6 & 0 to 9.4 & 0 to 18.4 & 0 to 108.5 \\
\hline $1^{2}(\%)$ & NA & 0 & 0 & NA & 0 & 0 & 84 \\
\hline \multicolumn{8}{|l|}{ Hypoxia } \\
\hline Events & $35 / 122$ & $140 / 6363$ & 20/791 & $8 / 306$ & $12 / 480$ & $4 / 2788$ & $16 / 544$ \\
\hline Estimate per 1000 & 260.1 & 18.9 & 34.1 & 32.0 & 12.6 & 1.7 & 26.2 \\
\hline $95 \% \mathrm{Cl}$ & 122.1 to 398.2 & 11.1 to 26.7 & 10.9 to 57.3 & 0 to 77.3 & 0 to 28.4 & 0.2 to 3.3 & 12.8 to 39.6 \\
\hline $1^{2}(\%)$ & 65 & 64 & 56 & 59 & 57 & 0 & 0 \\
\hline \multicolumn{8}{|l|}{ Intubation } \\
\hline Events & $0 / 110$ & $1 / 5681$ & $1 / 561$ & $0 / 306$ & $0 / 68$ & 0/1954 & $2 / 456$ \\
\hline Estimate per 1000 & 0 & 0.3 & 1.6 & 0 & 0 & 0 & 5.3 \\
\hline $95 \% \mathrm{Cl}$ & 0 to 40.5 & 0 to 0.8 & 0 to 5 & 0 to 14.9 & 0 to 64 & 0 to 2.4 & 0 to 11.9 \\
\hline $\mathrm{I}^{2}(\%)$ & 0 & 0 & 0 & 0 & 0 & 0 & 0 \\
\hline
\end{tabular}




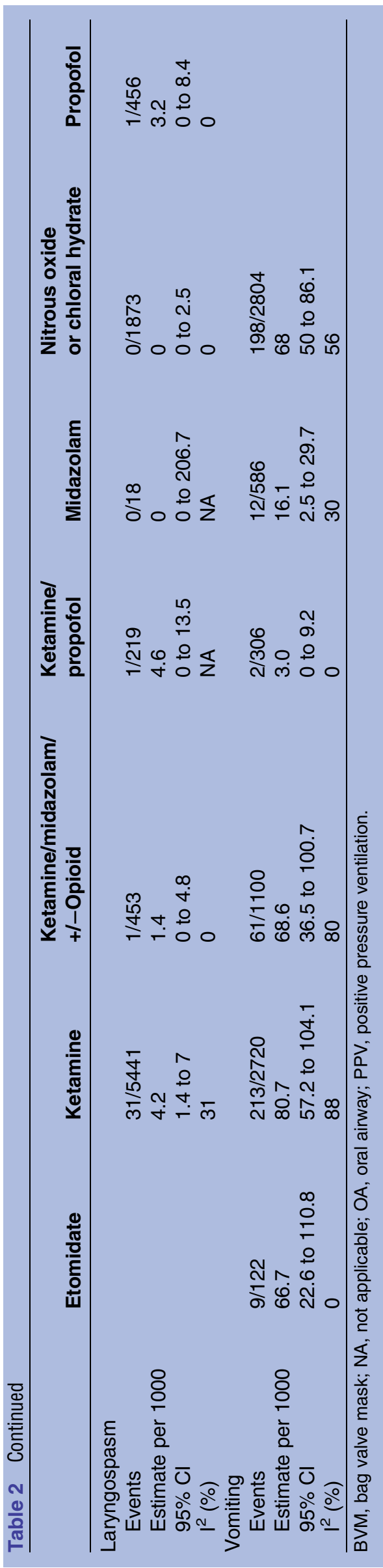

monitoring. ${ }^{5} 72627$ The purpose of this review was to synthesise existing data to provide incidence rates of events that are infrequent when reported in individual studies. In addition, it was our goal to focus on the past 10 years of data in order to capture contemporary medication trends and monitoring practices for PSA in the ED. We included 41 different studies comprising nearly 14000 sedations.

There were no reports of any paediatric deaths during PSA in the ED in the included studies over the past 10 years. In 1983, there were three paediatric deaths in the same dental office due to a combination of medications given for dental procedures. These deaths led to the development of the first sedation guidelines published by the AAP in $1985 .{ }^{28}$ In 2001, there was a report of an infant who had been overdosed with demerol, phenergan and thorazine (DPT) in the ED, went into cardiac arrest and recovered subsequently. ${ }^{29}$ The Pediatric Sedation Research Consortium reported no deaths in over 38000 sedations performed by emergency physicians. ${ }^{30}$ Death from PSA in the ED is a rare event; diligent monitoring performed by clinicians with skills necessary to rescue from deeper levels of sedation are important factors in performing PSA safely.

Agitation occurred in 1.8\% of children undergoing PSA in the ED. This was seen most frequently with midazolam on nearly $20 \%$ of sedations. Midazolam has a long history of causing 'paradoxical reactions' or agitation. $^{31}$ The mechanism is thought to be due to the inhibition of the cortical restraint centres and decreased serotonin that may precipitate aggressive behaviour. ${ }^{32}$ Previous reports of agitation from midazolam alone have ranged from $6 \%$ to $42 \% .{ }^{33} 34$ We found that ketamine/ midazolam and ketamine/propofol had similar incidences of agitation (6\% and $4 \%$, respectively). Ketamine alone had about half of the incidence of agitation at 24.1 per 1000 sedations or $2.4 \%$ (95\% CI 1.3 to 3.5 ). Green et $a l^{35}$ reported severe agitation in $1.6 \%$ of patients receiving intramuscular ketamine. In a study by Sherwin $e t a l^{6}$ on agitation using ketamine with and without midazolam, it was found that midazolam had no additional benefit in decreasing recovery agitation. Our study supports this finding with a higher incidence of agitation with ketamine/midazolam than ketamine alone. The lowest rates of agitation were seen with nitrous oxide at 7.9 per 1000 sedations or $0.8 \%$ and propofol at 3.0 per 1000 sedations or $0.3 \%$. Nitrous oxide is known to have an opioid-like effect that occurs in addition to the sedative effect. ${ }^{37} 38$ The majority of the propofol studies were performed for fracture reduction and received opioids during their course. We found no events of agitation with etomidate; however, the meta-analysis included only two small studies. Other studies on etomidate have reported $0-4 \%$ incidence of agitation. $^{39} 40$ All medications used for PSA aim to depress awareness, and in so doing, it may inhibit control centres in the brain, resulting in agitation. In addition, preprocedural agitation has been significantly 


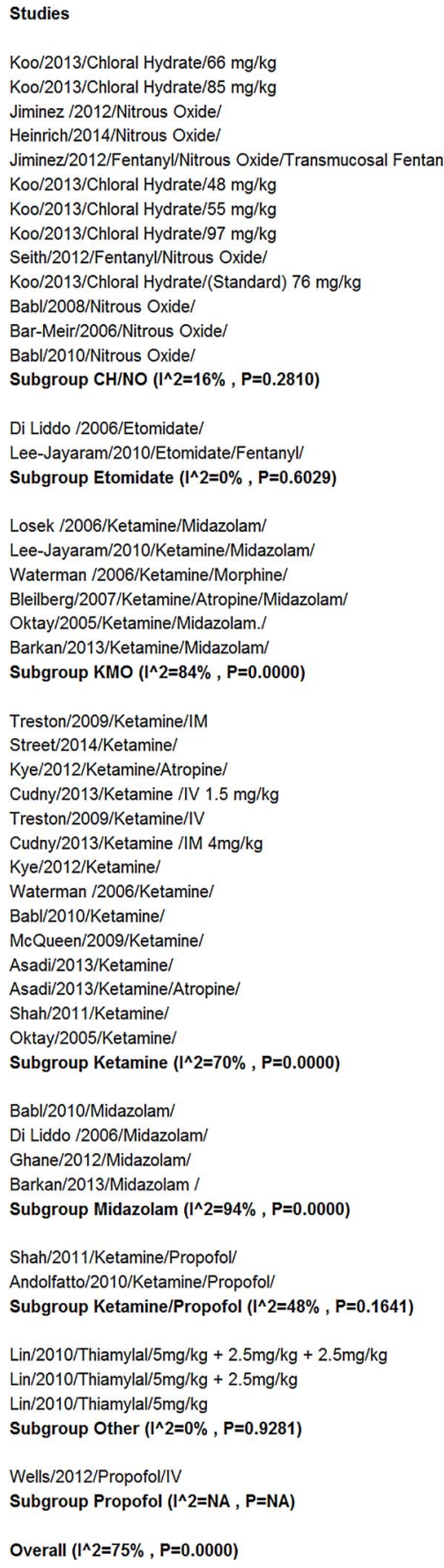

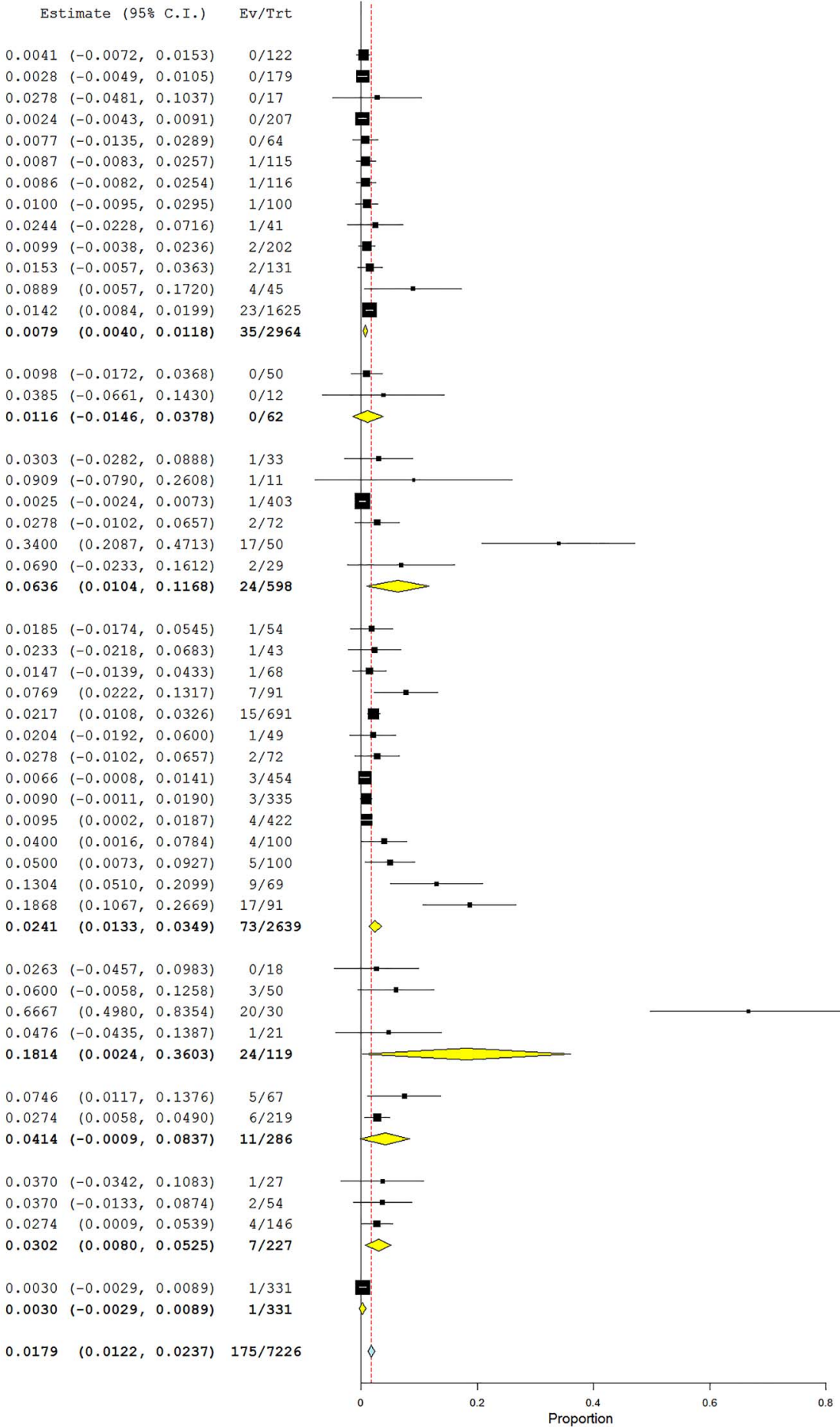

$0.0041(-0.0072,0.0153) \quad 0 / 122$

$0.0024(-0.0043,0.0091) \quad 0 / 20$

$0.0077(-0.0135,0.0289) \quad 0 / 64$

$0.0086(-0.0082,0.0254) \quad 1 / 11$

$.0100(-0.0095,0.0295)$

$0.0153(-0.0057,0.0363) \quad 2 / 131$

$(0.0057,0.1720)$

$0.0079(0.0040,0.0118) \quad 35 / 2964$

$0.0098(-0.0172,0.0368)$

$0.0385(-0.0661,0.1430)$

$0.0116(-0.0146,0.0378)$

$03(-0.0282,0.0888)$

$0.0909(-0.0790,0.2608)$

$0.0024,0.0073)$

$0.0690(-0.0233,0.1612)$

$6(0.0104,0.1168)$

$0.0185(-0.0174,0.0545)$

$.0769 \quad(0.0222,0.1317)$

$0.0217(0.0108,0.0326)$

$(-0.0008,0.0141)$

$0.0090(-0.0011,0.0190)$

$(0.0002,0.0187)$

$.0400 \quad(0.0016,0.0784)$

$0.0500 \quad(0.0073,0.0927)$

(0.0510, 0.2099$)$

$8 \quad(0.1067,0.2669)$

$0.0263+(-0.0457,0.0983)$

$0.0600(-0.0058,0.1258)$

$0.6667 \quad(0.4980,0.8354)$

$0.0476(-0.0435,0.1387)$

$0.1814(0.0024,0.3603)$

$0.0746 \quad(0.0117,0.1376)$

$0.0414(-0.0009,0.0837)$

$0.0370(-0.0342,0.1083)$

$0.0370(-0.0133,0.0874)$

$0.0274 \quad(0.0009,0.0539)$

$0.0030(-0.0029,0.0089)$

$0.0030(-0.0029,0.0089)$

Proportion

Figure 2 Meta-analysis of the outcome of agitation by study medication. $\mathrm{CH} / \mathrm{NO}$, chloral hydrate/nitrous oxide; Ev, number of events; IM, intramuscular; IV, intravenous; KMO, ketamine/midazolam/opioid; NA, not applicable; Trt, total number of children/ sedations.

associated with recovery agitation. ${ }^{36}$ Medication selection and patient predisposition are important factors in the decision process for PSA.

Apnoea occurred in $<1 \%$ and hypoxia in about $1.5 \%$ of children undergoing PSA. The majority of children were monitored with $\mathrm{ETCO}_{2}$ monitoring. The $\mathrm{ETCO}_{2}$ monitoring has been shown to detect apnoea and hypoventilation before hypoxia is detectable. ${ }^{41}$ The 2006 AAP guidelines 'encouraged' capnography, whereas both the ACEP and ASA have recommended routine use of capnography during all PSAs performed. ${ }^{5}$ Hypoxia was an adverse event that the majority of studies reported, where apnoea was reported in only about half of the studies. Ketamine was the medication used most frequently for PSA. Ketamine is unique in that it is a dissociative agent and does not follow the dose-dependent 
Studies

Heinrich/2014/Nitrous Oxide/ Asadi/2013/Ketamine/ Asadi/2013/Ketamine/Atropine/

Di Liddo /2006/Etomidate/

Di Liddo /2006/Midazolam/

Mandt/2012/Etomidate/Fentanyl/Overa

Kye/2012/Ketamine/Atropine/

Kye/2012/Ketamine/

Cudny/2013/Ketamine /IM 4mg/kg Jasiak/2012/Propofol/IV

Misra/2008/Ketamine/Midazolam/

Andolfatto/2010/Ketamine/Propofol/

Roback/2006/Ketamine/lV

Cudny/2013/Ketamine /IV $1.5 \mathrm{mg} / \mathrm{kg}$

Shah/2011/Ketamine/

Wells/2012/Propofol/IV

Shah/2011/Ketamine/Propofol/

Anderson/2007/Propofol/

Melendez/2009/Ketamine/IV or IM

Overall $\left(I^{\wedge} 2=25 \%, P=0.1499\right)$
Estimate (95\% C.I.) Ev/Trt

$0.0024(0.0000,0.0091) 0 / 207$

$0.0050(0.0000,0.0186) 0 / 100$

$0.0050(0.0000,0.0186) \quad 0 / 100$

$0.0098(0.0000,0.0368) 0 / 50$

$0.0098(0.0000,0.0368) \quad 0 / 50$

$0.0082(0.0000,0.0308) 0 / 60$

$0.0072(0.0000,0.0273) 0 / 68$

$0.0068(0.0000,0.0258) \quad 0 / 72$

$0.0204(0.0000,0.0600) \quad 1 / 49$

$0.0114(0.0000,0.0335) \quad 1 / 88$

$0.0093(0.0000,0.0273) \quad 1 / 108$

$0.0091(0.0000,0.0217) 2 / 219$

$0.0183(0.0000,0.0435) 2 / 109$

$0.0330(0.0000,0.0697) 3 / 91$

$0.0580(0.0028,0.1131) 4 / 69$

$0.0121(0.0003,0.0239) \quad 4 / 331$

$0.0746(0.0117,0.1376) 5 / 67$

$0.0400(0.0056,0.0744) \quad 5 / 125$

$0.0024(0.0009,0.0038) 10 / 4252$

$0.0071(0.0032,0.0110) 38 / 6215$

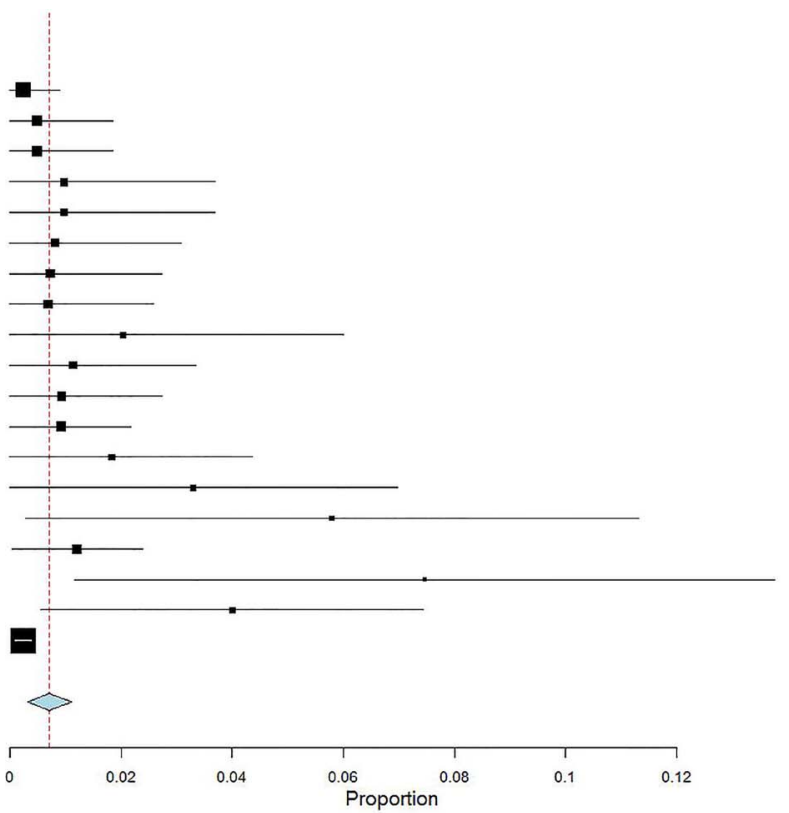

Figure 3 Meta-analysis of the outcome of apnoea by study. Ev, number of events; IM, intramuscular; IV, intravenous; Trt, total number of children/sedations.

sedation spectrum of minimal, moderate, deep and general anaesthesia. ${ }^{42}$ Ketamine/propofol and propofol alone had higher rates of apnoea than ketamine alone (3.4\% and $1.5 \%$ vs $0.5 \%$, respectively). This did not hold true for hypoxia, though, where ketamine/propofol, ketamine and propofol had a fairly similar incidence. ${ }^{43}$ Etomidate was found to have the highest rate of hypoxia at $26 \%$ of the PSAs. In all of the paediatric etomidate studies, fentanyl was administered at $1 \mu \mathrm{g} /$ $\mathrm{kg}$ just prior to the PSA. Further investigation is most likely needed to elucidate the role of adjunct opioids in paediatric PSA. The lowest incidence of hypoxia was seen with nitrous oxide at $0.2 \%$. This is not surprising, since the majority of nitrous oxide PSAs are in the minimal-to-moderate range of PSA and administered concomitantly with oxygen.

Studies
Seith/2012/Fentanyl/Nitrous Oxide/
Jiminez/2012/Fentanyl/Nitrous Oxide/Trans
Heinrich/2014/Nitrous Oxide/
Babl/2010/Nitrous Oxide/
Jiminez /2012/Nitrous Oxide/
Shah/2011/Ketamine/
Cudny/2013/Ketamine /IV $1.5 \mathrm{mg} / \mathrm{kg}$
Cudny/2013/Ketamine /IM 4mg/kg
Shah/2011/Ketamine/Propofol/
Sharieff/2007/Ketamine/Propofol/IV
Babl/2010/Midazolam/
Di Liddo /2006/Etomidate/
Mandt/2012/Etomidate/Fentanyl/Overall
Di Liddo /2006/Midazolam/
Babl/2010/Ketamine/
Melendez/2009/Ketamine/IV or IM
Andolfatto/2010/Ketamine/Propofol/
Waterman /2006/Ketamine/Morphine/
Jasiak/2012/Propofol/IV
Roback/2006/Ketamine//V
Asadi/2013/Ketamine/
Asadi/2013/Ketamine/Atropine/
Wells/2012/Propofol/IV
Anderson/2007/Propofol/
McKee/2008/Ketamine/
Overall (I^2=47\% , P=0.0050)

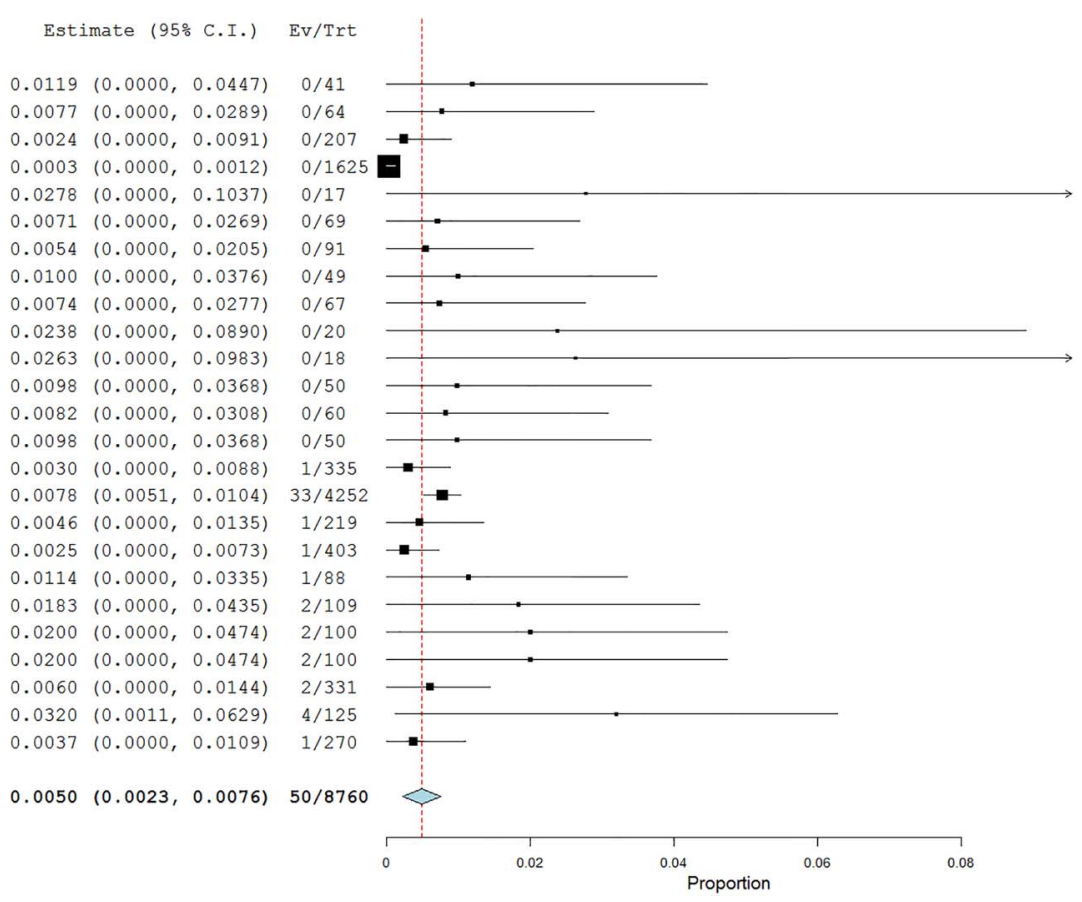

Figure 4 Meta-analysis of the outcome of bag valve mask, oral airway and positive pressure ventilation by study. Ev, number of events; IM, intramuscular; IV, intravenous; Trt, total number of children/sedations. 


\section{Studies}

Seith/2012/Fentany//Nitrous Oxide

Heinrich/2014/Nitrous Oxide/

Roback/2006/Ketamine/IV

Oktay/2005/Ketamine/Midazolam./

Roback/2006/Ketamine/IM

Wells/2012/Propofol/IV

Oktay/2005/Ketamine/

Misra/2008/Ketamine/Midazolam/

Andolfatto/2010/Ketamine/Propofol/

Mandt/2012/Etomidate/Fentanyl/Overall

Overall $\left(I^{\wedge} 2=0 \%, P=0.7563\right)$
Estimate (95\% C.I.) Ev/Trt

$0.0119(0.0000,0.0447) 0 / 41$

$0.0024(0.0000,0.0091) 0 / 207$

$0.0045(0.0000,0.0171) 0 / 109$

$0.0098(0.0000,0.0368) 0 / 50$

$0.0050(0.0000,0.0188) \quad 0 / 99$

$0.0030(0.0000,0.0089) 1 / 331$

$0.0110(0.0000,0.0324) 1 / 91$

$0.0093(0.0000,0.0273) 1 / 10$

$0.0091(0.0000,0.0217) 2 / 219$

$0.0667(0.0035,0.1298)$

$0.0045(0.0009,0.0081)$

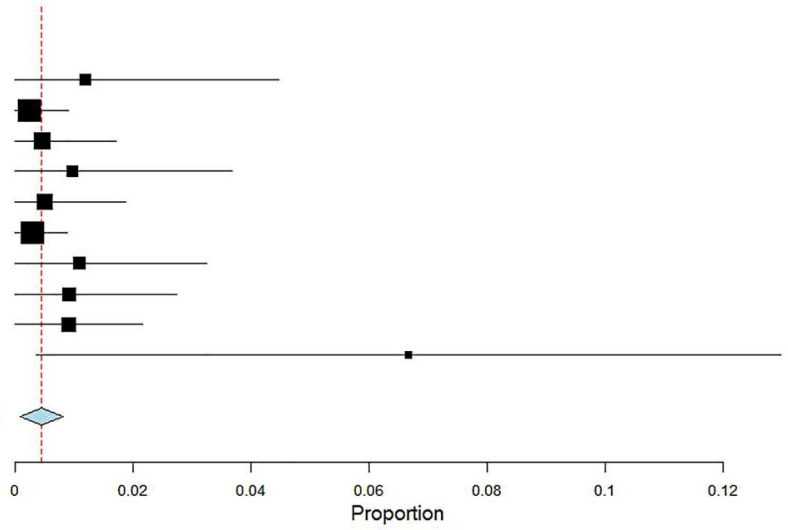

Figure 5 Meta-analysis of the outcome of bradycardia by study. Ev, number of events; IM, intramuscular; IV, intravenous; Trt, total number of children/sedations.

Basic airway interventions and BVM/oral airway/positive pressure ventilation were needed in 5.0 per 1000 sedations or $0.5 \%$ of PSAs. Intubation was rare and performed in 0.4 per 1000 sedations or $0.04 \%$ of PSAs. Propofol was the medication that had the highest incidence of basic and advanced airway interventions at $1 \%$ and $0.5 \%$, respectively. Interestingly, etomidate, which had the highest rate of hypoxia in our study, did not require any airway interventions other than supplemental oxygen.

Laryngospasm, which may require basic to advanced airway intervention, occurred in $0.3 \%$ of PSAs. This is similar to previous studies on ketamine that estimated the risk at $0.4-0.7 \%{ }^{44} 45$ Laryngospasm was treated most frequently with $\mathrm{BVM} /$ positive pressure airway. In one case, intubation was required. The majority of laryngospasm cases occurred with the use of ketamine. In the study with the highest incidence of laryngospasm, 20 $(69 \%)$ of the 29 patients with laryngospasm received intramuscular ketamine. $^{29}$ Nonetheless, laryngospasm does occur with other PSA medications such as propofol. ${ }^{46}$ In the largest study of paediatric propofol in a variety of settings, the rate of laryngospasm was $0.2 \%{ }^{12}$ Between $0.3 \%$ and $1.5 \%$ of children will have a

\begin{tabular}{|c|c|c|c|c|}
\hline Studies & Est & timate $(95 \%$ & $\%$ C.I.) & Ev/Trt \\
\hline Waterman /2006/Ketamine/Morphine/ & 0.0012 & $(-0.0022$, & $0.0047)$ & $0 / 403$ \\
\hline Dilli/2008/Ketamine/Midazolam/IV & 0.0208 & $(-0.0196$ & $0.0612)$ & $1 / 48$ \\
\hline Subgroup $\mathrm{KMO}\left(\mathrm{I}^{\wedge} 2=0 \%, \mathrm{P}=0.3436\right)$ & 0.0014 & $(-0.0020$ & $0.0048)$ & $1 / 451$ \\
\hline Waterman /2006/Ketamine/ & 0.0011 & $(-0.0019$ & $0.0041)$ & $0 / 454$ \\
\hline Dilli/2008/Ketamine/IV & 0.0096 & $(-0.0169$, & $0.0361)$ & $0 / 51$ \\
\hline Subgroup Ketamine $\left(\left.\right|^{\wedge} 2=0 \%, P=0.5318\right)$ & 0.0012 & $(-0.0018$ & $0.0042)$ & $0 / 505$ \\
\hline Seith/2012/Fentanyl/Nitrous Oxide/ & 0.0119 & $(-0.0209$ & $0.0447)$ & $0 / 41$ \\
\hline Heinrich/2014/Nitrous Oxide/ & 0.0024 & $(-0.0043$ & $0.0091)$ & $0 / 207$ \\
\hline Subgroup $\mathrm{CH} / \mathrm{NO}\left(\left.\right|^{\wedge} 2=0 \%, \mathrm{P}=0.5780\right)$ & 0.0028 & $(-0.0037$ & $0.0093)$ & $0 / 248$ \\
\hline Andolfatto/2010/Ketamine/Propofol/ & 0.0023 & $(-0.0040$ & $0.0086)$ & $0 / 219$ \\
\hline Subgroup Ketamine/Propofol $\left(I^{\wedge} 2=N A, P=N A\right)$ & 0.0023 & $(-0.0040$ & $0.0086)$ & $0 / 219$ \\
\hline Lane/2008/Midazolam/IN & 0.0024 & $(-0.0043$ & $0.0091)$ & $0 / 205$ \\
\hline Barkan/2013/Midazolam / & 0.0476 & $(-0.0435$ & $0.1387)$ & $1 / 21$ \\
\hline Subgroup Midazolam $\left(\left.\right|^{\wedge} 2=0 \%, P=0.3321\right)$ & 0.0027 & $(-0.0040$ & $0.0094)$ & $1 / 226$ \\
\hline Mandt/2012/Etomidate/Fentanyl/Overall & 0.0167 & $(-0.0157$ & $0.0491)$ & $1 / 60$ \\
\hline Subgroup Etomidate $\left(I^{\wedge} 2=N A, P=N A\right)$ & 0.0167 & $(-0.0157$ & $0.0491)$ & $1 / 60$ \\
\hline Wells/2012/Propofol/IV & 0.0060 & $(-0.0023$ & $0.0144)$ & $2 / 331$ \\
\hline Jasiak/2012/Propofol/IV & 0.0795 & $(0.0230$, & $0.1361)$ & $7 / 88$ \\
\hline Subgroup Propofol $\left(I^{\wedge} 2=84 \%, P=0.0117\right)$ & 0.0373 & $(-0.0340$ & $0.1085)$ & $9 / 419$ \\
\hline Overall $\left(\left.\right|^{\wedge} 2=8 \%, P=0.3679\right)$ & 0.0022 & $(0.0000$ & $0.0043)$ & $12 / 2128$ \\
\hline
\end{tabular}

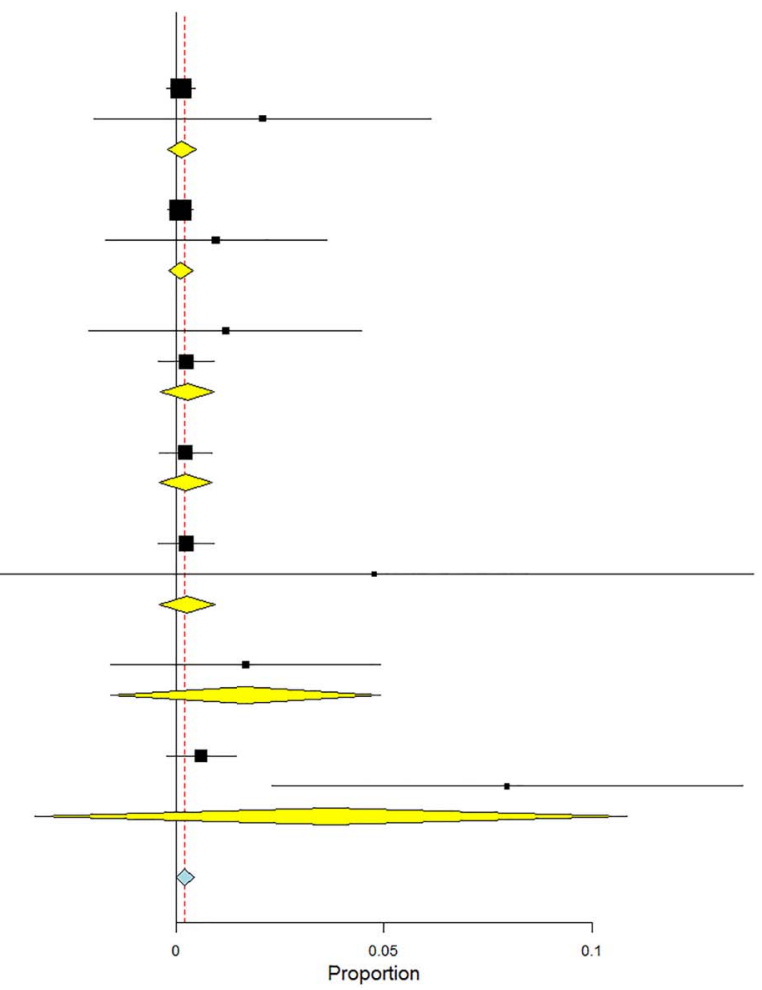

Figure 6 Meta-analysis of the outcome of hypotension by study and medication. $\mathrm{CH} / \mathrm{NO}$, chloral hydrate/nitrous oxide; Ev, number of events; IN, intranasal; IV, intravenous; KMO, ketamine/midazolam/opioid; NA, not applicable; Trt, total number of children/sedations. 
Studies

Waterman /2006/Ketamine/

Roback/2006/Ketamine/IM

McKee/2008/Ketamine/

Roback/2006/Ketamine/IV

Babl/2010/Ketamine/

Melendez/2009/Ketamine/IV or IM

Langhan/2011/Ketamine/

Street/2014/Ketamine/

Asadi/2013/Ketamine/

Chong/2013/Ketamine/Atropine/

Shah/2011/Ketamine/

Asadi/2013/Ketamine/Atropine

Cudny/2013/Ketamine /IM 4mg/kg

Cudny/2013/Ketamine /IV $1.5 \mathrm{mg} / \mathrm{kg}$

Dilli/2008/Ketamine/IV

Chong/2013/Ketamine/

Subgroup Ketamine $\left(I^{\wedge} 2=64 \%, P=0.0002\right.$

Di Liddo /2006/Midazolam

Ghane/2012/Midazolam/

Klein/2011/Midazolam/Oral

Klein /2011/Midazolam/IN

Klein/2011/Midazolam/Buccal

Lane/2008/Midazolam/IN

Babl/2010/Midazolam

Subgroup Midazolam (I^2=57\%, P=0.0311)

Jasiak/2012/Propofol/IV

Anderson/2007/Propofol/

Wells/2012/Propofol/IV

Subgroup Propofol $\left(I^{\wedge} 2=0 \%, P=0.3917\right)$

Mandt/2012/Etomidate/Fentanyl/Overall

Di Liddo /2006/Etomidate/

Lee-Jayaram/2010/Etomidate/Fentany/

Subgroup Etomidate $\left(I^{\wedge} 2=65 \%, P=0.0576\right)$

Lee-Jayaram/2010/Ketamine/Midazolam/ Barkan/2013/Ketamine/Midazolam/

Losek /2006/Ketamine/Midazolam/Morphine/

Bleilberg/2007/Ketamine/Atropine/Midazolam/

Dilli/2008/Ketamine/Midazolam/IV

Misra/2008/Ketamine/Midazolam/

Luhmann/2006/Ketamine/Midazolam

Waterman /2006/Ketamine/Morphine/

Losek /2006/Ketamine/Midazolam/

Subgroup KMO $\left(\left.\right|^{\wedge} 2=56 \%, P=0.0209\right)$

Shah/2011/Ketamine/Propofol/

Sharieff/2007/Ketamine/Propofol/IV

Andolfatto/2010/Ketamine/Propofol/

Subgroup Ketamine/Propofol $\left(I^{\wedge} 2=59 \%, P=0.0877\right)$

Chun/2009/Methohexital/

Chun/2009/Pentobarbital/

Subgroup Other $\left(I^{\wedge} 2=0 \%, P=1.0000\right)$

Babl/2010/Nitrous Oxide/

Heinrich/2014/Nitrous Oxide/

Jiminez /2012/Nitrous Oxide/

Koo/2013/Chloral Hydrate/66 mg/kg

Koo/2013/Chloral Hydrate/85 mg/kg

Koo/2013/Chloral Hydrate/48 mg/kg

Koo/2013/Chloral Hydrate/55 mg/kg

Koo/2013/Chloral Hydrate/97 mg/kg

Seith/2012/Fentanyl/Nitrous Oxide/

Jiminez/2012/Fentany//Nitrous Oxide/Transmucosal Fentany/

Koo/2013/Chloral Hydrate/(Standard) $76 \mathrm{mg} / \mathrm{kg}$

Subgroup $\mathrm{CH} / \mathrm{NO}\left(\mathrm{I}^{\wedge} \mathbf{2}=0 \%, \mathrm{P}=0.9756\right)$

Overall $\left(I^{\wedge} 2=76 \%, P=0.0000\right)$
Estimate (95\% C.T.)

$0.0066(-0.0008,0.0141) \quad 3 / 454$

$0.0404(0.0016,0.0792) \quad 4 / 99$

$0.0222(0.0046,0.0398) \quad 6 / 270$

$0.0826(0.0309,0.1342) \quad 9 / 109$

$0.0299(0.0116,0.0481) \quad 10 / 335$

$0.0190 \quad(0.0149,0.0232) \quad 81 / 4252$

$0.2759(0.1608,0.3909) \quad 16 / 58$

$0.0233(-0.0218,0.0683)$

$0.0200(-0.0074,0.0474) \quad 2 / 100$

$0.0122(-0.0046,0.0290) \quad 2 / 164$

$0.0290(-0.0106,0.0686) \quad 2 / 69$

$0.0200(-0.0074,0.0474) \quad 2 / 100$

$0.0204(-0.0192,0.0600) \quad 1 / 49$

$0.0054(-0.0096,0.0205) \quad 0 / 91$

$0.0096(-0.0169,0.0361) \quad 0 / 51$

$0.0084(-0.0080,0.0248) \quad 1 / 119$

$0.0189(0.0111,0.0267) 140 / 6363$

$0.2200 \quad(0.1052,0.3348) \quad 11 / 50$

$0.0161(-0.0282,0.0605) \quad 0 / 30$

$0.0083(-0.0147,0.0313) \quad 0 / 59$

$0.0083(-0.0147,0.0313) \quad 0 / 59$

$0.0083(-0.0147,0.0313) \quad 0 / 59$

$0.0049(-0.0047,0.0144) \quad 1 / 205$

$0.0263(-0.0457,0.0983) \quad 0 / 18$

$0.0126(-0.0032,0.0284) \quad 12 / 480$

$0.0341(-0.0038,0.0720) \quad 3 / 88$

$0.0480 \quad(0.0105,0.0855) \quad 6 / 125$

$0.0211 \quad(0.0056,0.0366) \quad 7 / 331$

$0.0262(0.0128,0.0396) \quad 16 / 544$

$0.3833(0.2603,0.5064) \quad 23 / 60$

$0.2000 \quad(0.0891,0.3109) \quad 10 / 50$

$0.1667 \quad(-0.0442,0.3775) \quad 2 / 12$

$0.2601 \quad(0.1221,0.3982) \quad 35 / 122$

$0.0417(-0.0714,0.1547) \quad 0 / 11$

$0.0345(-0.0319,0.1009) \quad 1 / 29$

$0.0312(-0.0290,0.0915) \quad 1 / 32$

$0.0417(-0.0045,0.0878) \quad 3 / 72$

$0.0625(-0.0060,0.1310) \quad 3 / 48$

$0.0278(-0.0032,0.0588) \quad 3 / 108$

$0.1091 \quad(0.0267,0.1915) \quad 6 / 55$

$0.0025(-0.0024,0.0073) \quad 1 / 403$

$0.0606(-0.0208,0.1420) \quad 2 / 33$

$0.0341 \quad(0.0109,0.0573) \quad 20 / 791$

$0.0448(-0.0047,0.0943) \quad 3 / 67$

$0.1500(-0.0065,0.3065) \quad 3 / 20$

$0.0091(-0.0035,0.0217) \quad 2 / 219$

$0.0320(-0.0133,0.0773) \quad 8 / 306$

$0.0476(-0.0435,0.1387) \quad 1 / 21$

$0.0476(-0.0168,0.1120) \quad 2 / 42$

$0.0476(-0.0050,0.1002) \quad 3 / 63$

$0.0012(-0.0005,0.0029) \quad 2 / 1625$

$0.0024(-0.0043,0.0091) \quad 0 / 207$

$0.0278(-0.0481,0.1037)-0 / 17$

$0.0041(-0.0072,0.0153) \quad 0 / 122$

$0.0028(-0.0049,0.0105) \quad 0 / 179$

$0.0043(-0.0076,0.0162) \quad 0 / 115$

$0.0043(-0.0075,0.0161) \quad 0 / 116$

$0.0050(-0.0087,0.0186) \quad 0 / 100$

$0.0119(-0.0209,0.0447) \quad 0 / 41$

$0.0156(-0.0148,0.0460)-1 / 64$

$0.0050(-0.0047,0.0146) \quad 1 / 202$

$0.0017 \quad(0.0002,0.0033) \quad 4 / 2788$

$0.0148(0.0102,0.0193) \quad 238 / 11457$

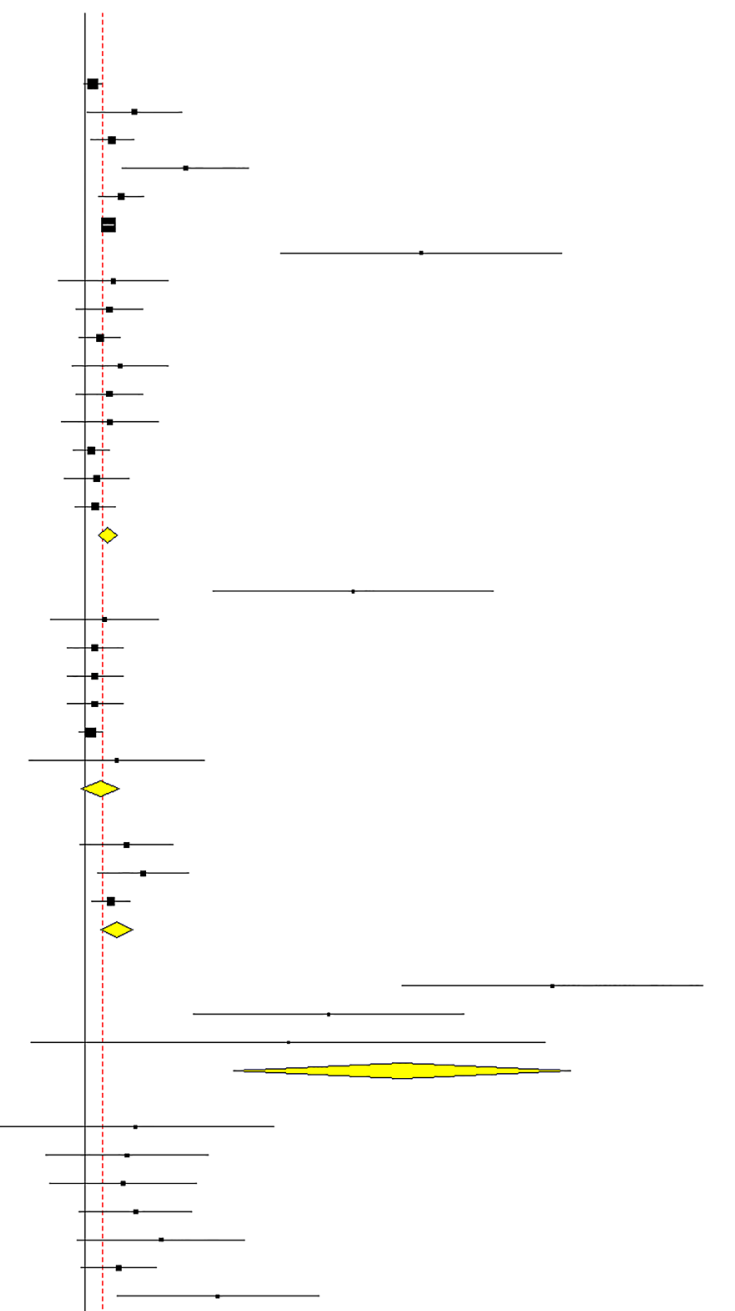

Figure 7 Meta-analysis of the outcome of hypoxia by study and medication. $\mathrm{CH} / \mathrm{NO}$, chloral hydrate/nitrous oxide; Ev, number of events; IM, intramuscular; IN, intranasal; IV, intravenous; KMO, ketamine/midazolam/opioid; Trt, total number of children/ sedations. 
Studies

Heinrich/2014/Nitrous Oxide/

Cudny/2013/Ketamine /IM 4mg/kg

Cudny/2013/Ketamine /IV $1.5 \mathrm{mg} / \mathrm{kg}$

Shah/2011/Ketamine/

Shah/2011/Ketamine/Propofol

Babl/2010/Midazolam/

Jiminez /2012/Nitrous Oxide/

Seith/2012/Fentanyl/Nitrous Oxide/

Jiminez/2012/Fentanyl/Nitrous Oxide/Transmucosal Fentanyl

Babl/2010/Nitrous Oxide/

Sharieff/2007/Ketamine/Propofol/IV

Babl/2010/Ketamine/

Di Liddo /2006/Etomidate/

Di Liddo /2006/Midazolam/

Mandt/2012/Etomidate/Fentanyl/Overall

Andolfatto/2010/Ketamine/Propofol/

Waterman /2006/Ketamine/Morphine/

Asadi/2013/Ketamine/

Asadi/2013/Ketamine/Atropine/

Anderson/2007/Propofol/

Kye/2012/Ketamine/Atropine/

Kye/2012/Ketamine/

Waterman /2006/Ketamine/

Oktay/2005/Ketamine/

Oktay/2005/Ketamine/Midazolam./

Melendez/2009/Ketamine/IV or IM

Misra/2008/Ketamine/Midazolam/

Wells/2012/Propofol/IV

Overall $\left(\left.\right|^{\wedge} 2=0 \%, P=0.9877\right)$
Estimate (95\% C.I.) Ev/Trt

$0.0024(0.0000,0.0091)$

$0.0100(0.0000,0.0376)$

$0.0054(0.0000,0.0205)$

$0.0071 \quad(0.0000,0.0269)$

$0.0074 \quad(0.0000,0.0277)$

$0.0263(0.0000,0.0983)$

$0.0278 \quad(0.0000,0.1037)$

$0.0119(0.0000,0.0447)$

$0.0077 \quad(0.0000,0.0289)$

$0.0003(0.0000,0.0012)$

$0.0238(0.0000,0.0890)$

$0.0015(0.0000,0.0056)$

$0.0098 \quad(0.0000,0.0368)$

$0.0098 \quad(0.0000,0.0368)$

$0.0082(0.0000,0.0308)$

$0.0023(0.0000,0.0086)$

$0.0012(0.0000,0.0047)$

$0.0050 \quad(0.0000,0.0186)$

$0.0050 \quad(0.0000,0.0186)$

$0.0040 \quad(0.0000,0.0149)$

$0.0072(0.0000,0.0273)$

$0.0068 \quad(0.0000,0.0258)$

$0.0011 \quad(0.0000,0.0041)$

$0.0054(0.0000,0.0205)$

$0.0098 \quad(0.0000,0.0368)$

$0.0002(0.0000,0.0007)$

$0.0093 \quad(0.0000,0.0273)$

$0.0060 \quad(0.0000,0.0144)$

$0.0004(-0.0000,0.0008)$

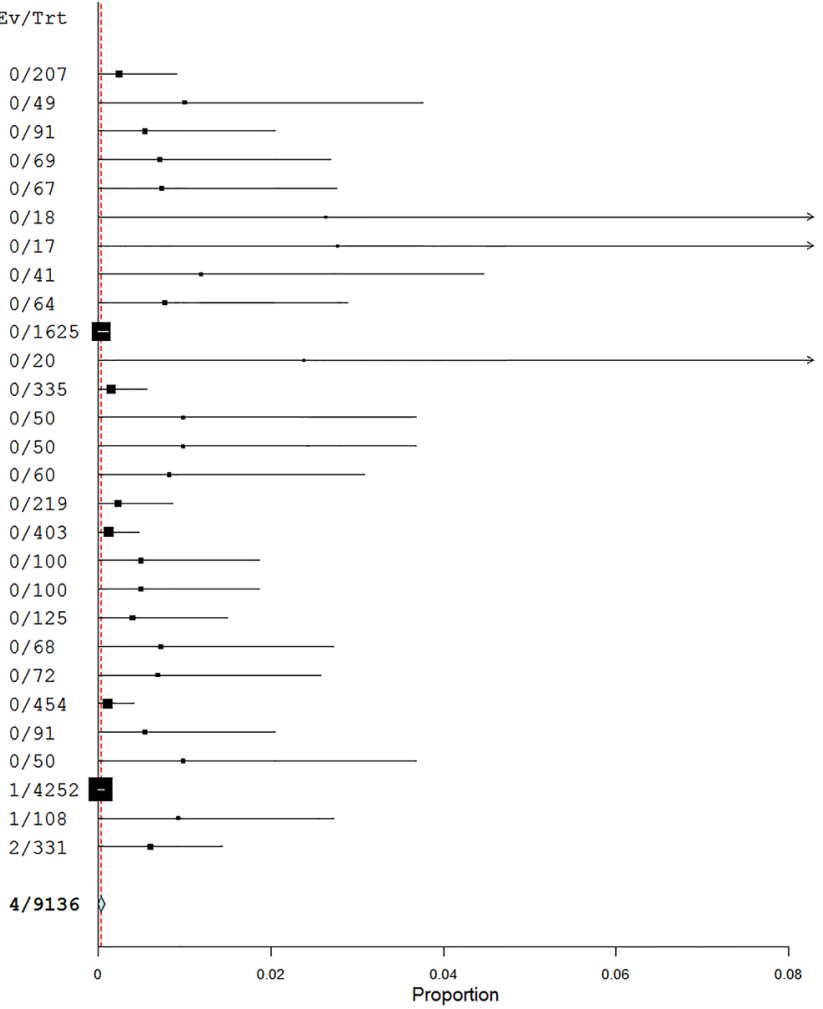

Figure 8 Meta-analysis of the outcome of intubation by study. Ev, number of events; IM, intramuscular; IV, intravenous; Trt, total number of children/sedations.

respiratory event during PSA. The majority will only require supplemental oxygen and airway repositioning. Advanced and basic airway skills will be required in up to $0.5 \%$ of sedations.

Vomiting occurred in $5.6 \%$ of paediatric PSAs performed in the ED. There were no occurrences of aspiration reported in the nearly 14000 patients reviewed. Recently, there was a report of laryngospasm with subsequent aspiration with nitrous oxide PSA in the ED. ${ }^{46}$ Ketamine did have a relatively high incidence of vomiting at $8 \%$, compared with all of the other medications, followed by nitrous oxide at $6.8 \%$. In previous

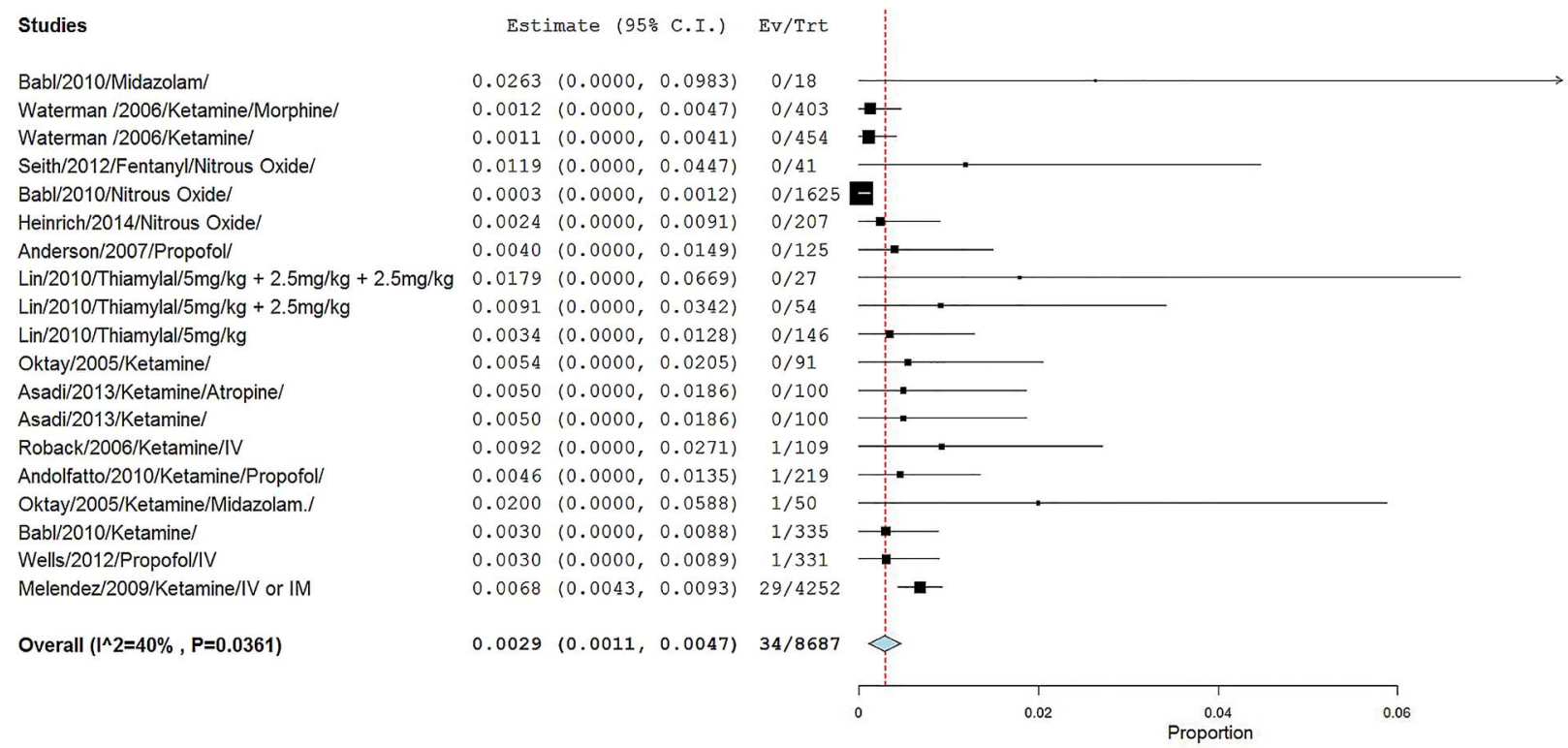

Figure 9 Meta-analysis of the outcome of laryngospasm by study. Ev, number of events; IM, intramuscular; IV, intravenous; Trt, total number of children/sedations. 
Studies

Babl/2010/Midazolam Lane/2008/Midazolam/IN Klein/2011/Midazolam/Oral Klein /2011/Midazolam/IN Klein/2011/Midazolam/Bucca Di Liddo /2006/Midazolam/ Subgroup Midazolam $\left(I^{\wedge} 2=20 \%, P=0.2843\right)$

Jiminez /2012/Nitrous Oxide/ Jiminez/2012/Fentanyl/Nitrous Oxide/Transmucosal Fentany Koo/2013/Chloral Hydrate/48 mg/kg Koo/2013/Chloral Hydrate/55 mg/kg Bar-Meir/2006/Nitrous Oxide/ Babl/2008/Nitrous Oxide/

Seith/2012/Fentanyl/Nitrous Oxide/ Koo/2013/Chloral Hydrate/97 mg/kg Koo/2013/Chloral Hydrate/66 mg/kg Luhmann/2006/Nitrous Oxide/ Koo/2013/Chloral Hydrate/85 mg/kg Koo/2013/Chloral Hydrate/(Standard) $76 \mathrm{mg} / \mathrm{kg}$ Babl/2010/Nitrous Oxide/ Subgroup $\mathrm{CH} / \mathrm{NO}\left(\mathrm{I}^{\wedge} 2=56 \%, \mathrm{P}=0.0071\right)$

Andolfatto/2010/Ketamine/Propofol/ Shah/2011/Ketamine/Propofol/ Sharieff/2007/Ketamine/Propofol/IV Subgroup Ketamine/Propofol $\left(I^{\wedge} 2=0 \%, P=0.4428\right)$

Lin $/ 2010 /$ Thiamylal $/ 5 \mathrm{mg} / \mathrm{kg}+2.5 \mathrm{mg} / \mathrm{kg}+2.5 \mathrm{mg} / \mathrm{kg}$ Lin $/ 2010 /$ Thiamylal $/ 5 \mathrm{mg} / \mathrm{kg}+2.5 \mathrm{mg} / \mathrm{kg}$ Lin/2010/Thiamylal/5mg/kg Subgroup Other $\left(I^{\wedge} 2=0 \%, P=0.8008\right)$

Cudny/2013/Ketamine /IV $1.5 \mathrm{mg} / \mathrm{kg}$ Chong/2013/Ketamine/Atropine/ Kye/2012/Ketamine/Atropine/ Chong/2013/Ketamine/ Lee/2012/Ketamine/IV Oktay/2005/Ketamine/ Waterman /2006/Ketamine/

Street/2014/Ketamine/ Asadi/2013/Ketamine/Atropine/ Kye/2012/Ketamine/

McKee/2008/Ketamine/

Cudny/2013/Ketamine /IM 4mg/kg

Shah/2011/Ketamine/

Asadi/2013/Ketamine/

Roback/2006/Ketamine/IV

Dilli/2008/Ketamine/IV

McQueen/2009/Ketamine/

Roback/2006/Ketamine/IM

Babl/2010/Ketamine/

Subgroup Ketamine $\left(I^{\wedge} 2=88 \%, P=0.0000\right)$

Lee-Jayaram/2010/Ketamine/Midazolam/

Misra/2008/Ketamine/Midazolam

Barkan/2013/Ketamine/Midazolam/

Bleilberg/2007/Ketamine/Atropine/Midazolam/

Waterman /2006/Ketamine/Morphine/

Oktay/2005/Ketamine/Midazolam.I

Dilli/2008/Ketamine/Midazolam/IV

McKee/2008/Ketamine/Analgesia/Oral Analgesia

Luhmann/2006/Ketamine/Midazolam/

McQueen/2009/Ketamine/Midazolam./

Subgroup $K M O\left(I^{\wedge} 2=80 \%, P=0.0000\right)$

Lee-Jayaram/2010/Etomidate/Fentanyl/ Mandt/2012/Etomidate/Fentanyl/Overall Di Liddo /2006/Etomidate/

Subgroup Etomidate $\left(I^{\wedge} 2=0 \%, P=0.6030\right)$

Misra/2008/Midazolam/Morphine/

McQueen/2009/Fentanyl/Midazolam

Subgroup Midazolam $\left(I^{\wedge} 2=0 \%, P=0.9733\right)$

Overall $\left(I^{\wedge} 2=85 \%, P=0.0000\right)$
Estimate (95\% C.I.)

$0.0263(-0.0457,0.0983)$

$0.0024(-0.0043,0.0091)$

$0.0169(-0.0160,0.0499)$

$0.0169(-0.0160,0.0499)$

$0.0169(-0.0160,0.0499)$

$0.0800 \quad(0.0048,0.1552)$

$0.0103(-0.0021,0.0226)$

$0.0278(-0.0481,0.1037)$

$0.0469(-0.0049,0.0987)$

$0.0261(-0.0030,0.0552)$

$0.0431 \quad(0.0061,0.0801)$

$0.1111(0.0193,0.2029)$

$0.0534 \quad(0.0149,0.0919)$

$0.1951 \quad(0.0738,0.3164)$

$0.0900 \quad(0.0339,0.1461)$

$0.0820 \quad(0.0333,0.1306)$

$0.2553(0.1307,0.3800)$

$0.0782(0.0389,0.1175) \quad 14 / 179$

$0.0891 \quad(0.0498,0.1284) \quad 18 / 202$

$0.0640 \quad(0.0521,0.0759) \quad 104 / 1625$

$0.0680(0.0500,0.0861) \quad 198 / 2804$

$0.0023(-0.0040,0.0086) \quad 0 / 219$

$0.0149(-0.0141,0.0440) \quad 1 / 67$

$0.0500(-0.0455,0.1455) \quad 1 / 20$

$0.0030(-0.0031,0.0092) \quad 2 / 306$

$0.0179(-0.0312,0.0669) \quad 0 / 27$

$0.0091(-0.0160,0.0342) \quad 0 / 54$

$0.0205(-0.0025,0.0436) \quad 3 / 146$

$0.0156(-0.0004,0.0316) \quad 3 / 227$

$0.0110(-0.0104,0.0324) \quad 1 / 91$

$0.0122(-0.0046,0.0290) \quad 2 / 164$

$0.0441(-0.0047,0.0929) \quad 3 / 68$

$0.0252(-0.0030,0.0534) \quad 3 / 119$

$0.2143(-0.0007,0.4292) \quad 3 / 14$

$0.0549 \quad(0.0081,0.1018) \quad 5 / 91$

$0.0132 \quad(0.0027,0.0237) \quad 6 / 454$

$0.1395 \quad(0.0360,0.2431) \quad 6 / 43$

$0.0700 \quad(0.0200,0.1200) \quad 7 / 100$

$0.0972 \quad(0.0288,0.1657) \quad 7 / 72$

$0.0259 \quad(0.0070,0.0449) \quad 7 / 270$

$0.1633(0.0598,0.2668) \quad 8 / 49$

$0.1159 \quad(0.0404,0.1915) \quad 8 / 69$

$0.1100 \quad(0.0487,0.1713) \quad 11 / 100$

$0.1193(0.0584,0.1801) \quad 13 / 109$

$0.2745(0.1520,0.3970) \quad 14 / 51$

$0.0592 \quad(0.0367,0.0818) \quad 25 / 422$

$0.2626(0.1759,0.3493) \quad 26 / 99$

$0.1731 \quad(0.1326,0.2137) \quad 58 / 335$

$0.0807 \quad(0.0572,0.1041) \quad 213 / 2720$

$0.0909(-0.0790,0.2608)$

$0.0278(-0.0032,0.0588)$

$0.1034(-0.0074,0.2143)$

$0.0417(-0.0045,0.0878)$

$0.0099 \quad(0.0002,0.0196)$

$0.0800 \quad(0.0048,0.1552)$

$0.1458 \quad(0.0460,0.2457)$

$0.0498 \quad(0.0197,0.0798)$

$0.2364(0.1241,0.3486)$

$0.1057 \quad(0.0514,0.1600)$

$0.0686(0.0365,0.1007)$

$0.0833(-0.0730,0.2397)$

$0.0500(-0.0051,0.1051)$

$0.1000 \quad(0.0168,0.1832)$

$0.0667 \quad(0.0226,0.1108)$

$0.0357(-0.0330,0.1045)$

$0.0370 \quad(0.0014,0.0727)$

$0.0368 \quad(0.0051,0.0684)$

$0.0555(0.0452,0.0658) \quad 498 / 7865$

$1 / 11$

$3 / 108$

$3 / 29$

$3 / 72$

$4 / 403$

$4 / 50$

$7 / 48$

$10 / 201$

$13 / 55$

$13 / 123$

$61 / 1100$

$1 / 12$

$3 / 60$

$5 / 50$

$9 / 122$

$1 / 28$

$4 / 108$

$5 / 136$
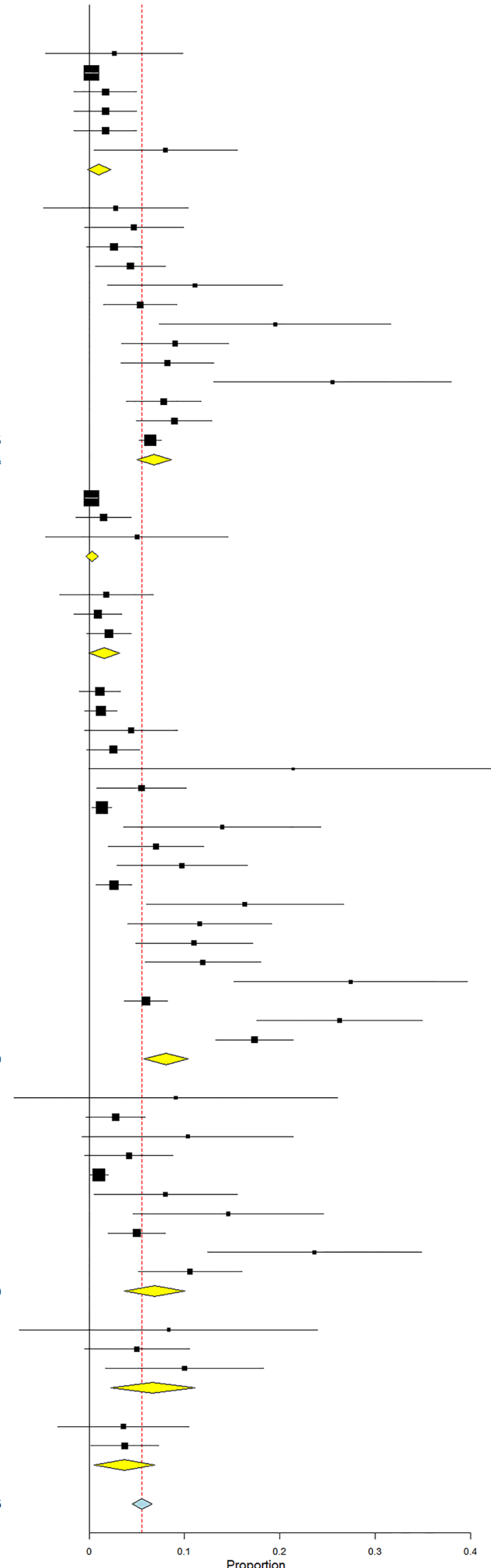

Figure 10 Meta-analysis of the outcome of vomiting by study and medication. $\mathrm{CH} / \mathrm{NO}$, chloral hydrate/nitrous oxide; Ev, number of events; IM, intramuscular; IN, intranasal; IV, intravenous; KMO, ketamine/midazolam/opioid; Trt, total number of children/sedations. 
paediatric ketamine studies, vomiting was estimated at $6.1-18.8 \%{ }^{47}{ }^{48}$ Ondansetron has been found to decrease ketamine associated vomiting from $12.6 \%$ to $4.7 \%$ in a double-blind placebo-controlled randomised study. ${ }^{49}$ Although vomiting is not a serious adverse effect, it is stressful for patients and families. This should be considered when obtaining informed consent and when involving the families and patients in shared decision-making.

Hypotension occurred in $0.2 \%$ and bradycardia in $0.5 \%$ of PSAs performed in the ED. Hypotension occurred most frequently with propofol and etomidate. Propofol is known to cause transient hypotension but rarely needs any intervention. ${ }^{50}$ Bradycardia was seen infrequently and was more common with etomidate. All but one of the episodes of bradycardia self-resolved. In a study of PSA in children aged $<2$ years by Misra $e t a l^{52}$ ketamine/midazolam was administered twice to a 2month old infant with recent bronchiolitis; the patient developed apnoea and bradycardia and was intubated.

In summary, serious adverse events and a need for advanced airway management are exceedingly rare in paediatric PSA in the ED. We hope this information will guide a physicians' choices of medication selection in PSA, facilitate risk communication at the time of informed consent and create a stronger background for shared decision-making.

\section{Limitations}

There are several potential limitations in our systematic review. (1) The major limitation is variation in the definitions for the outcomes that were provided in the studies. There is a lack of standardisation in the reporting of the outcomes by the original studies, and this might have affected the estimates. (2) Not all studies reported all the outcomes of interest in the meta-analysis. For example, the need for intervention after hypoxia, nausea and hypotension were not explicitly reported in each study. Multiple studies reported the need for supplemental oxygen or airway repositioning; however, we considered these as part of the sedation procedure and not as outcomes. (3) The RCTs reported higher incidences of adverse events; this is most likely due to more rigorous data collection procedures than in observational studies. Reporting pooled incidences of both RCTs and observational studies strengthens the statistical precision of the estimates and enhances the ability to provide incidence rates of events that are infrequent when reported in individual studies, which was one of the goals of this review. (4) We did not search for unpublished literature or ongoing trials. (5) We analysed each treatment arm as a separate study to be able to analyse by medication received; the cohorts did not overlap, so the patients were not counted twice in the analyses. Since each study arm received different medications and had different events, we included them as separate cohorts. This can introduce study correlation within the analyses. (6) This study is limited to adverse events in children up to age 18 , which could have included children who are physiologically adults. Data on adverse events in adults can be found in Bellolio et al. ${ }^{53}$

There are several possible sources of variability or heterogeneity among studies that are included in meta-analyses. Variability in the participants, the types or timing of outcome measurements, and intervention characteristics may be termed clinical heterogeneity; variability in the trial design and quality is typically termed methodological heterogeneity; variability in summary treatment effects between trials is termed statistical heterogeneity. Methodological and clinical sources of heterogeneity contribute to the magnitude and presence of statistical heterogeneity. Significant statistical heterogeneity arising from methodological heterogeneity suggests that the studies are not all estimating the same effects due to different degrees of bias.

Clinical heterogeneity arises from differences in participant characteristics (eg, sex, age, baseline disease severity, ethnicity, comorbidities), types or timing of outcome measurements and intervention characteristics (eg, dose and frequency of dose). This heterogeneity can cause significant statistical heterogeneity, inaccurate summary effects and associated conclusions, misleading decision-makers and others.

To decrease selection bias, we included all eligible studies, including those with low numbers of participants. This introduces heterogeneity into the analyses. We assessed clinical and statistical heterogeneity and accounted for this in the statistical analyses. There was moderate clinical heterogeneity and variable statistical heterogeneity, meaning that there was some variability in the intervention effects being evaluated in the different studies. Low statistical heterogeneity is desirable in a meta-analysis.

The outcomes chosen were those that were clinically important and clearly defined in most of the studies. Rigorous methodology was used in all steps of the data review and extraction process, which was conducted in duplicate by two independent reviewers.

\section{CONCLUSIONS}

Serious adverse events such as intubation and aspiration are very rare in paediatric procedural sedation in the ED. Before performing PSA, the clinician should discuss the risks, benefits, alternatives of the procedure and the planned sedation with the parent and patient, answering any questions that arise. Data from this review will help inform the clinician and the patient regarding the incidence of complications and side effects of PSA. These data provide quantitative risk estimates to facilitate shared decision-making, risk communication and informed consent as well as resource allocation for PSA in the ED.

The safest and most effective medication or combination of medications for sedation is yet to be 
determined. No single drug is ideal for all situations. Consensus for standardising definitions for reporting adverse events in procedural sedation among paediatric patients needs to be reached and implemented in order to better determine optimal agents for specific clinical indications. ${ }^{8}$

\section{Author affiliations}

${ }^{1}$ Department of Emergency Medicine, Mayo Clinic, Rochester, Minnesota, USA ${ }^{2}$ Robert D. and Patricia E. Kern Center for the Science of Health Care Delivery, Mayo Clinic, Rochester, Minnesota, USA

${ }^{3}$ Universidade Federal das Ciências da Saúde de Porto Alegre, Porto Alegre, Brazil

${ }^{4}$ Division of Preventive, Occupational and Aerospace Medicine, Department of Medicine, Mayo Clinic, Rochester, Minnesota, USA

${ }^{5}$ Department of Health Sciences Research, Mayo Clinic, Rochester, Minnesota, USA

${ }^{6}$ Mayo Clinic Libraries, Rochester, Minnesota, USA

Twitter Follow M. Fernanda Bellolio at @mfbellolio and Henrique Puls at @henrique_puls

Contributors MFB contributed to the study concept and design; acquisition, analysis and interpretation of the data; drafting of the manuscript; critical revision of the manuscript for important intellectual content as a whole; statistical expertise; administrative, technical, or material support and to the study supervision. HAP contributed to the acquisition of the data and drafting of the manuscript. JLA contributed to the analysis and interpretation of the data; drafting of the manuscript and to the critical revision of the manuscript for important intellectual content. WIG contributed to the acquisition of the data. MHM contributed to the analysis and interpretation of the data; critical revision of the manuscript for important intellectual content; statistical expertise and to the study supervision. PB contributed to the acquisition, analysis and interpretation of the data. PJE contributed to the critical revision of the manuscript for important intellectual content related to the literature search and to the administrative, technical, or material support. ZW contributed to the analysis and interpretation of the data and to the statistical expertise. EPH contributed to the study concept and design; critical revision of the manuscript for important intellectual content in the discussion; administrative, technical, or material support and to the study supervision.

Funding This research received no specific grant from any funding agency in the public, commercial or not-for-profit sectors.

Competing interests None declared.

Provenance and peer review Not commissioned; externally peer reviewed.

Data sharing statement This is a systematic review of published articles. No additional data are available.

Open Access This is an Open Access article distributed in accordance with the Creative Commons Attribution Non Commercial (CC BY-NC 4.0) license, which permits others to distribute, remix, adapt, build upon this work noncommercially, and license their derivative works on different terms, provided the original work is properly cited and the use is non-commercial. See: http:// creativecommons.org/licenses/by-nc/4.0/

\section{REFERENCES}

1. Krauss B, Green SM. Procedural sedation and analgesia in children. Lancet 2006;367:766-80.

2. Biber JL, Allareddy V, Allareddy V, et al. Prevalence and predictors of adverse events during procedural sedation anesthesia-outside the operating room for esophagogastroduodenoscopy and colonoscopy in children: age is an independent predictor of outcomes. Pediatr Crit Care Med 2015;16:e251-9.

3. Monroe KK, Beach M, Reindel R, et al. Analysis of procedural sedation provided by pediatricians. Pediatr Int 2013;55:17-23

4. Cravero JP, Blike GT, Beach M, et al. Incidence and nature of adverse events during pediatric sedation/anesthesia for procedures outside the operating room: report from the pediatric sedation research consortium. Pediatrics 2006;118:1087-96.

5. Cote CJ, Wilson S, American Academy of Pediatrics, American Academy of Pediatric Dentistry, Work Group on Sedation. Guidelines for monitoring and management of pediatric patients during and after sedation for diagnostic and therapeutic procedures: an update. Pediatrics 2006;118:2587-602.

6. Godwin SA, Caro DA, Wolf SJ, et al. Clinical policy: procedural sedation and analgesia in the emergency department. Ann Emerg Med 2005;45:177-96.

7. Godwin SA, Burton JH, Gerardo CJ, et al. Clinical policy: procedural sedation and analgesia in the emergency department. Ann Emerg Med 2014;63:247-58 e18.

8. Bhatt M, Kennedy RM, Osmond MH, et al. Consensus-based recommendations for standardizing terminology and reporting adverse events for emergency department procedural sedation and analgesia in children. Ann Emerg Med 2009;53:426-35 e4.

9. Mason KP, Green SM, Piacevoli Q. International Sedation Task Force. Adverse event reporting tool to standardize the reporting and tracking of adverse events during procedural sedation: a consensus document from the World SIVA International Sedation Task Force. $\mathrm{Br}$ $J$ Anaesth 2012;108:13-20.

10. Cote CJ, Karl HW, Notterman DA, et al. Adverse sedation events in pediatrics: analysis of medications used for sedation. Pediatrics 2000;106:633-44.

11. Cote CJ, Notterman DA, Karl HW, et al. Adverse sedation events in pediatrics: a critical incident analysis of contributing factors. Pediatrics 2000;105(4 Pt 1):805-14.

12. Cravero JP, Beach ML, Blike GT, et al. Pediatric Sedation Research Consortium. The incidence and nature of adverse events during pediatric sedation/anesthesia with propofol for procedures outside the operating room: a report from the Pediatric Sedation Research Consortium. Anesth Analg 2009;108:795-804.

13. Sahyoun C, Krauss B. Clinical implications of pharmacokinetics and pharmacodynamics of procedural sedation agents in children. Curr Opin Pediatr 2012;24:225-32.

14. Wheeler M, Cote CJ, Todres ID. The pediatric airway. In: Cote CJ, Lerman J, Todres ID, eds. A practice of anesthesia for infants and children. $4^{\text {th }}$ edn. Philadelphia: Saunders Elsevier, 2009.

15. Pacheco GS, Ferayorni A. Pediatric procedural sedation and analgesia. Emerg Med Clin North Am 2013;31:831-52.

16. Fleisher GR, Ludwig S. Textbook of pediatric emergency medicine. Philadelphia: Wolters Kluwer/Lippincott Williams \& Wilkins Health, 2010.

17. Marcus CL, Glomb WB, Basinski DJ, et al. Developmental pattern of hypercapnic and hypoxic ventilatory responses from childhood to adulthood. J Appl Physiol, 1994;76:314-20.

18. Green SM, Andolfatto G, Krauss B. Ketofol for procedural sedation? Pro and con. Ann Emerg Med 2011;57:444-8.

19. Mandt MJ, Roback MG, Bajaj L, et al. Etomidate for short pediatric procedures in the emergency department. Pediatr Emerg Care 2012;28:898-904.

20. McQueen A, Wright RO, Kido MM, et al. Procedural sedation and analgesia outcomes in children after discharge from the emergency department: ketamine versus fentanyl/midazolam. Ann Emerg Med 2009;54:191-97.e1-4

21. Moher D, Liberati A, Tetzlaff J, et al. Preferred Reporting Items for Systematic Reviews and Meta-analyses: the PRISMA statement. Open Med 2009;3:e123-30.

22. Higgins JPT, Green S. Cochrane handbook for systematic reviews of interventions version 5.1.0 [updated March 2011]. The Cochrane Collaboration, 2011

23. Wells GA, Shea B, O'Connell D, et al. Quality assessment scales for observational studies. Ottawa Health Research Institute, 2004.

24. Wallace BC, Dahabreh IJ, Trikalinos TA, et al. Closing the gap between methodologists and end-users: $\mathrm{R}$ as a computational back-end. J Stat Softw 2012;49:1-15.

25. Cravero JP, Havidich JE. Pediatric sedation-evolution and revolution. Paediatr Anaesth 2011:21:800-9.

26. Ramaiah R, Bhananker S. Pediatric procedural sedation and analgesia outside the operating room: anticipating, avoiding and managing complications. Expert Rev Neurother 2011;11:755-63.

27. American Society of Anesthesiologists Task Force on Sedation and Analgesia by Non-Anesthesiologists. Practice guidelines for sedation and analgesia by non-anesthesiologists. Anesthesiology 2002;96:1004-17.

28. Coté CJ. Sedation protocols-why so many variations? Pediatrics 1994:94:281-3.

29. Brown ET, Corbett SW, Green SM. latrogenic cardiopulmonary arrest during pediatric sedation with meperidine, promethazine, and chlorpromazine. Pediatr Emerg Care 2001;17:351-3. 
30. Couloures KG, Beach M, Cravero JP, et al. Impact of provider specialty on pediatric procedural sedation complication rates. Pediatrics 2011;127:e1154-60

31. Hall RC, Zisook S. Paradoxical reactions to benzodiazepines. Br J Clin Pharmacol 1981;11(Suppl 1):99S-104S

32. Mancuso CE, Tanzi MG, Gabay M. Paradoxical reactions to benzodiazepines: literature review and treatment options. Pharmacotherapy 2004;24:1177-85.

33. Davies FC, Waters M. Oral midazolam for conscious sedation of children during minor procedures. J Accid Emerg Med 1998;15:244-8.

34. Roelofse JA, Joubert JJ, Roelofse PG. A double-blind randomized comparison of midazolam alone and midazolam combined with ketamine for sedation of pediatric dental patients. J Oral Maxillofac Surg 1996;54:838-44; discussion 45-6.

35. Green SM, Rothrock SG, Lynch EL, et al. Intramuscular ketamine for pediatric sedation in the emergency department: safety profile in 1,022 cases. Ann Emerg Med 1998;31:688-97.

36. Sherwin TS, Green SM, Khan A, et al. Does adjunctive midazolam reduce recovery agitation after ketamine sedation for pediatric procedures? A randomized, double-blind, placebo-controlled trial. Ann Emerg Med 2000;35:229-38.

37. Emmanouil DE, Dickens AS, Heckert RW, et al. Nitrous oxide-antinociception is mediated by opioid receptors and nitric oxide in the periaqueductal gray region of the midbrain. Eur Neuropsychopharmacol 2008:18:194-9.

38. Emmanouil DE, Quock RM. Advances in understanding the actions of nitrous oxide. Anesth Prog 2007;54:9-18.

39. Disel NR, Yilmaz HL, Sertdemir Y, et al. Etomidate versus ketamine: effective use in emergency procedural sedation for pediatric orthopedic injuries. Pediatr Emerg Care 2015.

40. Dickinson R, Singer AJ, Carrion W. Etomidate for pediatric sedation prior to fracture reduction. Acad Emerg Med 2001;8: 74-7.

41. Deitch K, Miner J, Chudnofsky $\mathrm{CR}$, et al. Does end tidal $\mathrm{CO}_{2}$ monitoring during emergency department procedural sedation and analgesia with propofol decrease the incidence of hypoxic events? A randomized, controlled trial. Ann Emerg Med 2010;55:258-64.
42. Green SM, Krauss B. Ketamine is a safe, effective, and appropriate technique for emergency department paediatric procedural sedation. Emerg Med J 2004;21:271-2.

43. Miner JR, Danahy M, Moch A, et al. Randomized clinical trial of etomidate versus propofol for procedural sedation in the emergency department. Ann Emerg Med 2007;49:15-22.

44. Melendez E, Bachur R. Serious adverse events during procedural sedation with ketamine. Pediatr Emerg Care 2009;25:325-8.

45. Green SM, Rothrock SG, Harris T, et al. Intravenous ketamine for pediatric sedation in the emergency department: safety profile with 156 cases. Acad Emerg Med 1998;5:971-6.

46. Babl FE, Grindlay J, Barrett MJ. Laryngospasm with apparent aspiration during sedation with nitrous oxide. Ann Emerg Med 2015;66:475-8

47. Roback MG, Wathen JE, Bajaj L, et al. Adverse events associated with procedural sedation and analgesia in a pediatric emergency department: a comparison of common parenteral drugs. Acad Emerg Med 2005;12:508-13.

48. Roback MG, Wathen JE, MacKenzie T, et al. A randomized, controlled trial of i.v. versus i.m. ketamine for sedation of pediatric patients receiving emergency department orthopedic procedures. Ann Emerg Med 2006; 48:605-12.

49. Langston WT, Wathen JE, Roback MG, et al. Effect of ondansetron on the incidence of vomiting associated with ketamine sedation in children: a double-blind, randomized, placebo-controlled trial. Ann Emerg Med 2008;52:30-4.

50. Bassett KE, Anderson JL, Pribble CG, et al. Propofol for procedural sedation in children in the emergency department. Ann Emerg Med 2003;42:773-82.

51. Jasiak KD, Phan H, Christich AC, et al. Induction dose of propofol for pediatric patients undergoing procedural sedation in the emergency department. Pediatr Emerg Care 2012;28:440-2.

52. Misra S, Mahajan PV, Chen X, et al. Safety of procedural sedation and analgesia in children less than 2 years of age in a pediatric emergency department. Int J Emerg Med 2008;1:173-7.

53. Bellolio MF, Gilani WI, Barrionuevo P, et al. Incidence of adverse events in adults undergoing procedural sedation in the emergency department: a systematic review and meta-analysis. Acad Emerg Med 2016;23:119-34. 